(2) Open Access Full Text Article

\title{
Uses and benefits of omega-3 ethyl esters in patients with cardiovascular disease
}

REVIEW

This article was published in the following Dove Press journal:

Journal of Multidisciplinary Healthcare

5 July 2010

Number of times this article has been viewed

\section{Giacomo Levantesi \\ Maria Giuseppina Silletta \\ Roberto Marchioli \\ Laboratory of Clinical Epidemiology of Cardiovascular Disease, Consorzio Mario Negri Sud, Chieti, Italy}

\begin{abstract}
Much evidence on the favorable effects of omega-3 ethyl esters on cardiovascular morbidity and mortality has been obtained in studies performed in healthy subjects and in different clinical settings. Here the clinical effects of omega-3 ethyl ester administration in patients with previous myocardial infarction or heart failure are reviewed, together with a discussion of underlying mechanisms of action. The pharmacokinetic and pharmacodynamic properties of omega-3 ethyl esters, as well as evidence concerning their safety and tolerability, are also reported.
\end{abstract}

Keywords: omega-3 ethyl esters, myocardial infarction, heart failure

\section{Introduction}

Since the first evidence showing a protective effect against coronary artery disease (CAD), reported more than 30 years ago, ${ }^{1,2}$ several epidemiologic and clinical studies have indicated an inverse relationship between a diet rich in fish and cardiovascular (CV) morbidity and mortality. ${ }^{3-8}$ Two compounds of the omega-3 fatty acid class, namely eicosapentaenoic acid (EPA) and docosahexaenoic acid (DHA), were presumed to be the active ingredients in fish. ${ }^{9}$ In the early 1980 s, a large-scale method to purify EPA and DHA in the chemical form of an ethyl ester (EE) was developed for clinical use. Since then, several studies have investigated the role of isolated and combined EPA and DHA in the form of EE, especially with respect to CV disease prevention. Overall the results of these studies indicated a protective effect of omega-3 EE on total mortality and CV events.

In many European countries, oral omega-3 EE administration is indicated in adult patients for secondary prevention after myocardial infarction (MI) and for the treatment of hypertriglyceridemia. In the US, omega-3 EE prescription is indicated for the treatment of triglyceride (TG) levels $\geq 500 \mathrm{mg} / \mathrm{dL}$.

The purpose of this article is to review the pharmacologic properties of oral omega-3 EE, describing briefly the evidence for omega-3 EE and hypertriglyceridemia, and focusing attention on their efficacy and tolerability in secondary prevention after MI and in patients with heart failure (HF).

\section{Triglycerides and cardiovascular risk}

Evidence from observational and experimental studies suggests a relationship between triglycerides (TG) and CV disease. ${ }^{10-13}$ In the female population of the Framingham study, there was an increase in $\mathrm{CV}$ event rates as TG levels increased. In men the correlation was not evident, although there was a $40 \%$ increase in incidence of coronary 
events as TG increased up to $200 \mathrm{mg} / \mathrm{dL}$, without a further increase of risk at higher levels. ${ }^{10}$

Findings from the Münster Heart Study (PROCAM) showed that coronary event rates increased as TG levels increased from $<200 \mathrm{mg} / \mathrm{dL}$ to $800 \mathrm{mg} / \mathrm{dL}$, but decreased significantly above this level. ${ }^{11}$ When TG levels were evaluated as a continuous variable, their level was not correlated with event rates. This finding likely reflects different atherogenicity of TG-rich lipoproteins at different TG levels; at the highest TG levels ( $>800 \mathrm{mg} / \mathrm{dL})$, less atherogenic chylomicrons predominate compared with the more atherogenic ones predominating in subjects with TG $<800 \mathrm{mg} / \mathrm{dL}$. Austin et al reported the existence of two low-density lipoprotein cholesterol (LDL-C) phenotypic distributions in relation to TG levels, ie, a less atherogenic phenotype A, characterized by large buoyant LDL particles that predominate with low TG levels, and a highly atherogenic phenotype B represented by small dense LDL particles that is prevalent with increased plasma levels of TG. ${ }^{14}$

The Baltimore Coronary Observational Long-Term Study was a long-term (20-year) study that evaluated predictors of coronary events in individuals who had documented CAD. ${ }^{13}$ TG, as well as diabetes mellitus, were found to be important predictors, with a TG level $>100 \mathrm{mg} / \mathrm{dL}$ increasing the risk for coronary events by $50 \%$ (95\% confidence interval $[\mathrm{CI}]$ : 1.1-2.1). After exclusion of diabetic patients, TG remained a significant predictor of new CAD events (relative risk [RR] 1.8, 95\% CI: 1.2-2.7).

The combined effect of baseline TG and lipoprotein cholesterol levels on the incidence of $\mathrm{CV}$ endpoints was studied in the Helsinki Heart Trial. After five years of follow-up, the combination of LDL-C to highdensity lipoprotein cholesterol (HDL-C) ratio $>5$ with $\mathrm{TG}>200 \mathrm{mg} / \mathrm{dL}$ revealed a subgroup of subjects at high $\mathrm{CV}$ risk (RR 3.8, 95\% CI: 2.2-6.6). ${ }^{15}$ Some clinical studies, but not all, reported a reduction of the risk of $\mathrm{CV}$ events by treatment with a fibric acid derivate in patients with high TG.

In patients with documented CAD, the Bezafibrate Infarction Prevention trial (BIP) tested the effect of bezafibrate (400 mg/day) on a combined endpoint including death from CAD or nonfatal MI. ${ }^{16}$ The primary endpoint in BIP was not affected by fibrate therapy, although it induced a significant $15.4 \%$ increase in HDL-C, and a significant $6.2 \%$ decrease in LDL-C. However, when data from the subset of patients with baseline TG $>200 \mathrm{mg} / \mathrm{dL}$ were analyzed, a significant $40 \%$ reduction in the primary endpoint was observed. ${ }^{16}$

At variance with previous studies, the benefit reported in the Veterans Affairs High-Density Lipoprotein Intervention trial (VA-HIT) did not appear to be correlated with TG reduction. ${ }^{17}$ In patients with $\mathrm{CAD}$, there was an overall $22 \%$ reduction in the rates for fatal and nonfatal $\mathrm{MI}$ or death from CAD in subjects randomized to gemfibrozil. However, multiple regression analyses failed to find a consistent link between TG and CAD event rates for all levels of TG. ${ }^{17,18}$

More recently, a post hoc analysis of PROVE IT-TIMI 22, a study which compared the effects of standard versus intensive statin therapy on the incidence of $\mathrm{CV}$ events in patients hospitalized for an acute coronary syndrome (ACS), evaluated the relationship at 30 days between on-treatment TG levels, LDL-C, and a composite endpoint of death, MI, and recurrent ACS. ${ }^{12}$ On-treatment TG $<150 \mathrm{mg} / \mathrm{dL}$ was independently associated with a lower risk of recurrent $\mathrm{CHD}$ events (adjusted hazards ratio [HR] 0.80, 95\% CI: 0.66-0.97, $P=0.025)$. For each $10 \mathrm{mg} / \mathrm{dL}$ decrement in TG the risk of the composite endpoint was lowered by $1.6 \%(P<0.001)$ after adjustment for LDL-C. These results supported the concept that achieving low TG, beyond low LDL-C, may deserve additional consideration in patients after ACS.

\section{Cardioprotective effects of omega-3 ethyl esters}

Since the first evidence of a protective effect on CAD, many studies of fish intake or daily administration of fish oils have reported an inverse relationship with $\mathrm{CV}$ morbidity and mortality. ${ }^{3-8,19}$

In the early 1980s, EPA and DHA became available for clinical use in the purified chemical form of EE. Each $1000 \mathrm{mg}$ capsule of omega-3 EE contains approximately $460 \mathrm{mg}$ of EPA EE and $380 \mathrm{mg}$ of DHA EE. ${ }^{20}$ Oral capsules of omega-3 EE, although providing fewer nutritional elements than fish, have the advantage of avoiding the possible negative effects of contaminants contained in fish (eg, dioxins, mercury, and polychlorinated biphenyls), ${ }^{21,22}$ the different action of various concentrations of EPA and DHA, and finally the effects of other fatty acids usually contained in fish oils. Since the commercialization of omega-3 EE, several studies have investigated isolated and combined preparations of EPA and DHA in the form of EE, especially with respect to $\mathrm{CV}$ prevention. Taken together, the results of the more recent studies confirmed that omega-3 fatty acids have cardioprotective effects, ${ }^{8,19,23-27}$ with an inverse correlation between risk of CAD events and quantity of DHA in plasma and cellular phospholipids, which is closely linked to the DHA content of the myocardium. ${ }^{28}$

Oral omega-3 EE is able to improve the lipid profile principally by reducing TG levels. However, in the 
major studies, changes in TC and HDL-C were generally not clinically significant, with a small net increase in LDL-C associated with a shift toward less atherogenic LDL subfractions.

In patients with previous $\mathrm{MI}$, the addition to recommended treatment (eg, angiotensin-converting enzyme [ACE] inhibitors, antiplatelet agents, $\beta$-blockers, statins) of oral omega-3 EE $1000 \mathrm{mg} /$ day was effective for secondary prevention, reducing the risk of the composite endpoint of death + nonfatal $\mathrm{MI}+$ nonfatal stroke as well as various other endpoints (including death, CV death, and sudden death). ${ }^{23,29}$ Post hoc results of analysis of individual events in the composite endpoint, as well as the time-course assessment of benefit of omega-3 EE, suggest that the reduction in the risk of fatal events following omega-3 EE contribute importantly to the significant reductions observed in the risk of the composite efficacy endpoints. The $45 \%$ reduction in the risk of sudden death was the major component in the reduction in risk of death shown in GISSI-Prevenzione.

The recent publication of the GISSI-HF trial results ${ }^{26}$ confirmed previous less consistent evidence ${ }^{30-33}$ about a possible benefit of omega-3 EE in patients with HF. After a median follow-up of 3.9 years, $850-882 \mathrm{mg}$ daily of EPA and DHA as EE induced a statistically significant risk reduction in mortality and mortality + admission to hospital for a $\mathrm{CV}$ reason. Almost half of the absolute reduction of risk attributable to treatment was due to the reduction of ventricular arrhythmias, although the benefit in both mortality and hospitalization suggests that omega-3 EE might also positively affect the pathophysiologic mechanisms leading to the progression of HF.

Despite the results of many studies indicating cardioprotective effects of omega-3 fatty acids, a Cochrane review ${ }^{34}$ and a meta-analysis ${ }^{35}$ seem not to confirm these benefits. The Cochrane review, ${ }^{34}$ which included 89 studies (48 randomized controlled studies and 41 cohort studies), found that omega3 EE did not induce a significant reduction in the risk of total mortality (RR 0.87 ; 95\% CI: $0.73-1.03$ ) or combined CV events (RR 0.95; 95\% CI: 0.82-1.12). The choice of inclusion of the DART (Diet and Reinfarction Trial) II in the analysis has generated considerable debate. ${ }^{27,36,37}$ After excluding DART II from the Cochrane analysis, the reduction of total death became statistically significant (RR 0.83; 95\% CI: $0.75-0.91)$, but the risk of $\mathrm{CV}$ events did not change. ${ }^{34}$ We updated the metanalysis of Leon et $\mathrm{al}^{38}$ including two recent clinical trials, GISSI-HF and OMEGA trial. We found that Omega-3 EE was associated with a $14 \%$ (OR 0.86; 95\% CI 0.79-0.94) significant risk reduction of death from cardiac cause and with barely not statistically significant risk reduction of all cause mortality (odds ratio [OR] 0.92; 95\% CI: 0.83-1.03) (Figure 1), confirming findings reported by Leon et al. ${ }^{38}$ Of note, the beneficial effects on risk of $\mathrm{CV}$

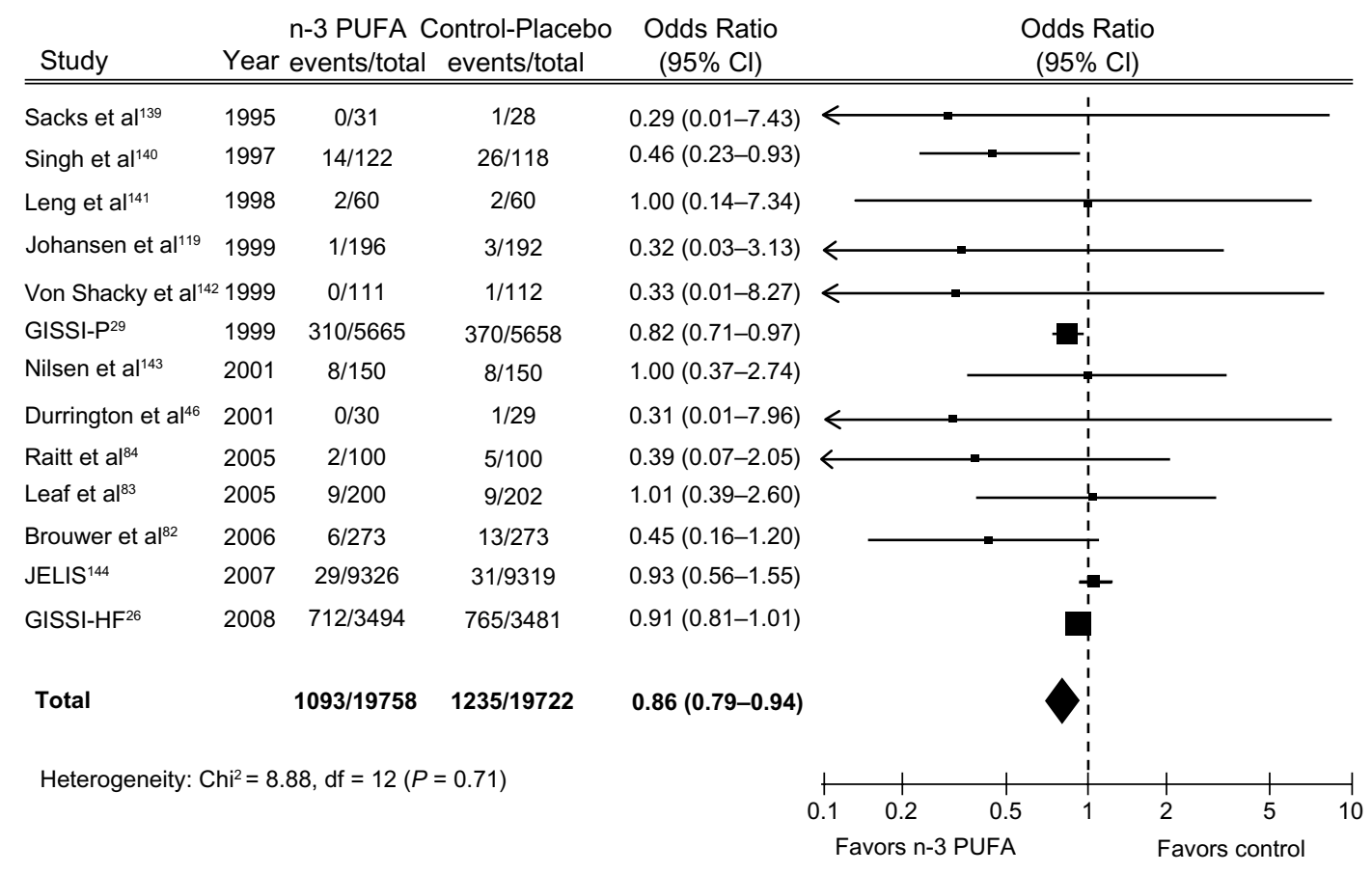

Figure I Randomized controlled trials reporting the effect of n-3 PUFA on cardiac death Abbreviations: $\mathrm{Cl}$, confidence interval; PUFA, polyunsaturated fatty acids. 
disease (CVD) appeared strong in the analysis of trials of secondary prevention, but not in those of the primary one. ${ }^{39}$ This finding should be considered against the efficacy of omega-3 fatty acids in primary CVD prevention. In fact, only $50 \%$ of the causes of death are usually due to CVD in this clinical setting and are therefore potentially modifiable by omega-3 fatty acids. However, this finding, and the higher proportion of deaths due to CV causes in patients with CVD, translate into very different benefits on total mortality in patients with or without CVD.

\section{Pharmacology}

\section{Pharmacokinetic properties}

Oral administration of omega-3 EE to healthy volunteers ${ }^{40-42}$ and hypertriglyceridemic subjects ${ }^{42}$ is followed by EPA and DHA absorption. After a first complete hydrolysis of omega-3 EE, EPA and DHA are absorbed and incorporated into plasma phospholipids and cholesterol esters, as reported in animal studies. ${ }^{20}$ Omega-3 EE oral administration in healthy volunteers for 12 weeks determined significant dosedependent increases in plasma phospholipid EPA and DHA content. ${ }^{43}$ The same increases in plasma/serum phospholipid EPA and DHA content were seen in various patient populations receiving oral omega-3 EE, such as those with combined hyperlipidemia, ${ }^{44}$ severe hypertriglyceridemia, ${ }^{45}$ $\mathrm{CAD},{ }^{46}$ essential hypertension, ${ }^{47}$ and hypertensive heart transplant recipients. ${ }^{48}$

EPA and DHA concentrations in plasma phospholipids are related to the level of EPA and DHA incorporated into cell membranes. ${ }^{20}$ Omega-3 fatty acids are metabolized via three main pathways. Fatty acids are first transported to the liver for incorporation into lipoproteins, and then channeled to peripheral lipid stores. Secondly, cell membrane phospholipids are replaced by lipoprotein phospholipids, allowing EPA to act as a precursor for eicosanoids of the cyclo-oxygenase and lipoxygenase pathways. ${ }^{20,24,49}$ Finally, omega-3 fatty acids, like all other fatty acids, are oxidized to meet energy requirements. ${ }^{20,24}$ Uptake of EPA and DHA into serum phospholipids in recipients of omega-3 EE concentrate was independent of age ( $<49$ versus $\geq 49$ years), and tended to be greater in women than in men. ${ }^{42}$

In healthy volunteers, the concomitant administration of omega-3 EE concentrate did not alter the steady-state pharmacokinetics of atorvastatin (and its major active metabolites, 2-hydroxyatorvastatin and 4-hydroxyatorvastatin), ${ }^{50}$ rosuvastatin, ${ }^{51}$ and simvastatin (and its major active metabolite, $\beta$-hydroxysimvastatin). ${ }^{52}$ To support these findings, experimental studies showed that undetectable concentrations
$(<1 \mu \mathrm{mol} / \mathrm{L})$ of the free forms of EPA and DHA are present in the circulation, so avoiding clinically significant inhibition of cytochrome P450 (CYP) enzymes. ${ }^{42}$

\section{Pharmacodynamic properties}

Although the mechanism of action of omega-3 fatty acids, including omega-3 EE, is not fully understood, ${ }^{40,42}$ a number of effects of omega-3 EE that can positively interfere with the development or worsening of $\mathrm{CV}$ disease have been reported. Available evidence seems to suggest that EPA and DHA might differ in the mechanisms by which they exert their beneficial effect on the CV system. This hypothesis needs to be carefully assessed and confirmed. ${ }^{53}$ In this review we discuss mechanisms which are likely to contribute to the benefit of omega-3 EE in post-MI and HF patients, including effects on lipid levels, cardiac electrophysiology and hemodynamics, blood pressure, endothelial function, thrombosis/homeostasis, and atherogenesis and inflammation.

\section{Lipid levels}

Omega-3 EE improved the lipid profile in patients with mixed dyslipidemia, ${ }^{54}$ familial combined hyperlipidemia, ${ }^{55}$ and hypertriglyceridemia. ${ }^{56-59}$ Significant reductions in TG, total cholesterol, non-HDL-C, very LDL-C (VLDL-C), VLDL-triglyceride and/or apoliprotein-B levels, and significant elevation in plasma or serum HDL-C and/or LDL-C levels with omega-3 EE 4000 mg/ day, alone ${ }^{56-59}$ or in combination with simvastatin $40 \mathrm{mg} /$ day $^{54}$ were evident.

Similar data were reported in a review that demonstrated a dose-dependent reduction in TG levels in clinical studies. ${ }^{60}$ In most studies, a 10\%-33\% reduction in TG levels was seen, that tended to be greater in studies of patients with higher TG levels at baseline. Total cholesterol and HDL-C did not significantly change, whilst a slight increase in LDL-C levels occurred. ${ }^{60}$

Omega-3 EEs exert a triglyceride-lowering effect through two main mechanisms. ${ }^{40}$ Firstly omega-3 EE may reduce the hepatic synthesis of TG inhibiting acyl CoA:1,2-diacylglycerol acyltransferase,${ }^{61}$ with reduced esterification and release of other fatty acids. ${ }^{20,61}$ Secondly, omega-3 EEs increase hepatic $\beta$-oxidation and upregulate fatty acid metabolism in the liver by stimulating peroxisome proliferator-activated receptor (PPAR) subtypes. ${ }^{62-64}$ This in turn reduces the availability of free fatty acids for TG synthesis and reduces TG levels. ${ }^{20}$ Omega-3 EE also affects other nuclear receptors involved in the modulation 
of TG levels, so they may increase the removal of TG from circulating VLDL via enzymatic upregulation. ${ }^{65}$

The elevation in LDL-C levels observed with omega3 EE seems to result from conversion of VLDL-C. ${ }^{66}$ In a study of 24 dyslipidemic obese patients, treatment with omega-3 EE $4000 \mathrm{mg} /$ day significantly increased the mean conversion rate of VLDL-apoliprotein B to intermediate density lipoprotein (IDL)-apoliprotein B and LDL-apoliprotein $\mathrm{B}$, as well as the mean conversion rate of IDL-apoliprotein $\mathrm{B}$ to LDL-apoliprotein B. ${ }^{67}$ Of note, the observed increase in LDL-C levels typically reflects a shift to larger, less atherogenic LDL particles. ${ }^{68}$ In patients with hypertriglyceridemia, despite the treatment with simvastatin $40 \mathrm{mg} /$ day, those randomized to receive omega-3 EE $4000 \mathrm{mg} /$ day for eight weeks showed a significantly greater median LDL particle size increase than patients on placebo. The direction of the shift in LDL particle size seemed to depend on the TG level; median changes in LDL particle size from baseline were $+0.60,+0.40,+0.15$, and $-0.20 \mathrm{~nm}$ in patients with on-treatment TG levels of $<149$, 149-192, 193-246, and $\geq 246 \mathrm{mg} / \mathrm{dL}$, respectively. In the same subgroups of patients, LDL subfraction pattern B (ie, smaller particles) was present in $68 \%, 79 \%, 93 \%$, and $73 \%$ of patients at endpoint. ${ }^{69}$ Similar results were observed in a study ${ }^{54}$ conducted in patients with mixed hyperlipidemia, ie, omega-3 EE $4000 \mathrm{mg} /$ day + simvastatin $20 \mathrm{mg} /$ day induced a significant $(P<0.05)$ increase from baseline in least-square mean LDL particle size compared with placebo + simvastatin $20 \mathrm{mg}$ /day, with no between-group difference in LDL particle concentration. Significantly greater reductions from baseline in VLDL particle size and concentration were also observed between the two treatment groups. Both omega-3 EE $4000 \mathrm{mg}$ /day and oral gemfibrozil $1200 \mathrm{mg}$ /day improved the atherogenic LDL subfraction profile of patients with hypertriglyceridemia, elevating the cholesterol content of the more buoyant, less atherogenic LDL-1, LDL-2, and LDL-3 subfractions versus baseline. No significant differences in the LDL-4 and LDL-5 subfractions versus baseline and no between-group differences in the cholesterol levels of the LDL subfractions were observed. ${ }^{59}$ In patients with familial combined hyperlipidemia, omega-3 EE treatment increased the LDL-C/apoliprotein-B ratio, indicating an elevation in the more buoyant and coreenriched LDL-1 and LDL-2 subfractions, although the average LDL particle size was unchanged. ${ }^{55}$

\section{Cardiac electrophysiology Heart rate}

According to the results of a meta-analysis,${ }^{70}$ omega-3 fatty acids (median dosage $3500 \mathrm{mg}$ /day), significantly reduced heart rate by 1.6 beats per minute compared with placebo. Subgroup analysis showed this effect to be influenced by baseline heart rate; in patients with a mean heart rate $\geq 69$ beats per minute at baseline there was a significant $(P<0.001)$ reduction of 2.5 beats per minute, with no significant change in patients with a mean heart rate of $<69$ beats per minute at baseline. ${ }^{70}$

\section{Arrhythmias}

The antiarrhythmic effect is believed to be the main mechanism explaining the reduced risk of sudden cardiac death seen in patients with recent MI treated with omega-3 EE in the GISSI-Prevenzione study ${ }^{23}$ This apparent antiarrhythmic effect may result from a number of mechanisms.

Experimental evidence suggests that $\mathrm{n}-3$ polyunsaturated fatty acids (PUFA) administered in the diet, added to culture media, or given intravenously, have direct effects on the trafficking of ion channels in cardiac membranes which may result in antiarrhythmic activity. ${ }^{71}$ The peculiarity of this action is that n-3 PUFA are likely to have a number of effects which could be pro- as well as antiarrhythmic. The sum of all these activities in modulating the electrical machinery of cardiac cells produces a positive "final" effect on life-threatening arrhythmias. The current hypothesis is that omega-3 EEs stabilize the electrical activity of myocytes by elevating the action potential threshold (ie, a stronger electrical stimulus is required to elicit an action potential), shortening the action potential duration, and prolonging the relative refractory time. The major contributors to the antiarrhythmic actions of omega-3 EE occur via inhibition of the voltage-dependent $\mathrm{Na}^{+}$currents, which initiate the action potential in excitable tissue. The beginning of the action potential may be also avoided, reducing delayed afterdepolarization through an inhibition of L-type $\mathrm{Ca}^{++}$currents which prevent $\mathrm{Ca}^{++}$overload. n-3 PUFA have also been reported to inhibit some potassium current components, such as the two repolarizing $\mathrm{K}^{+}$currents, the initial outward $\mathrm{K}^{+}\left(I_{\mathrm{to}}\right)$ current, and the delayed rectifier $\mathrm{K}^{+}\left(I_{\mathrm{K}}\right)$ current, as well as the transient outward current responsible for the early repolarization phase. n-3 PUFA have been found to have an inhibitory effect on the cardiac $\mathrm{Na}^{+} / \mathrm{Ca}^{++}$ exchange (NCX) current. NCX protein expression in its forward mode $\left(I_{\mathrm{NCX}}\right)$ provides a mechanism for extruding calcium from the cytosol and facilitates diastolic relaxation, and is often increased in patients with end-stage HF and with atrial fibrillation (AF). ${ }^{72}$ Decreased $I_{\mathrm{NCX}}$ may therefore result in a decreased propensity to develop delayed after 
depolarization and may contribute to the antiarrhythmic effects of n-3 PUFA.

The inhibition of intercellular communication may represent an additional potential antiarrhythmic mechanism of n-3 PUFA. Treatment with n-3 PUFA reduced vulnerability to induction of AF in a dog model by reducing atrial expression of connexin. ${ }^{73}$

Furthermore, a cell membrane shift in the balance of n-3 PUFA to $n-6$ PUFA might attenuate the production of $n-6$ PUFA-derived eicosanoids, including thromboxane A2 and prostaglandins, which have been suggested to promote arrhythmias. ${ }^{74,75}$

Finally, omega-3 EEs may reduce arrhythmic events modulating autonomic tone. ${ }^{25,76}$ This hypothesis seems to be corroborated by some studies on heart rate variability (HRV), a risk marker for sudden cardiac death. Omega-3 fatty acids content of cell membranes was positively correlated with $\mathrm{HRV},{ }^{77}$ and oral supplementation with $5200 \mathrm{mg} /$ day of omega-3 fatty acids for three months in patients with recent MI significantly increased HRV. ${ }^{78}$ In patients with healed MI and left ventricular dysfunction, omega-3 fatty acids $1500 \mathrm{mg} /$ day significantly improved HRV in the high-frequency band, compared with placebo, although there was no improvement in overall HRV. ${ }^{79}$ At variance with the previous evidence are the results of two studies showing that omega-3 EE at a daily dose of $1000 \mathrm{mg}$ for three months in patients with mild hypertension ${ }^{80}$ and of $3000 \mathrm{mg}$ for four months in post-MI patients, ${ }^{81}$ did not alter HRV indices to a significant extent.

Some recent studies in patients with an implantable cardioverter defibrillator (ICD) reported mixed results for an antiarrhythmic effect of omega-3 EE. ${ }^{82-84}$ Primary endpoints relating to the risk of ventricular arrhythmias ICD intervention for ventricular fibrillation or ventricular tachycardia ${ }^{82-84}$ or death ${ }^{82,83}$ were not improved by omega-3 EE to a significant extent. But when "probable" ventricular arrhythmic events were also considered, a significant $31 \%$ reduction in the primary endpoint was seen with omega- $3 \mathrm{EE} .{ }^{83}$

It has been hypothesized that omega-3 fatty acids may have more favorable effects in certain subpopulations, in which the specific clinical setting and underlying arrhythmogenic mechanisms of initiation and propagation may be more susceptible to the antiarrhythmic effects of omega-3 EE. It should be noted, for example, that patients enrolled in ICD trials were different from those in GISSI-Prevenzione. ${ }^{23}$ The best evidence for the antiarrhythmic action of n-3 PUFA has been produced by experimental work performed in ischemiamediated animal models and in clinical trials carried out in
post-MI patients in which ischemia-triggered arrhythmias may be predominant.

In addition, chronic oral dosing of omega-3 fatty acids, compared with acute or intravenous administration, may have different effects on cardiac electrophysiology, as suggested by experimental data showing that incorporation of n-3 PUFA into membrane phospholipids shortened the action potential without altering calcium transients and diastolic calcium levels in myocytes isolated from pigs. ${ }^{72}$ It has been hypothesized that tissue levels of n-3 PUFA may influence the effects of oral administration of omega-3 EE; low basal tissue levels consequent to a daily intake $<750 \mathrm{mg}$ might amplify the antiarrhythmic effect of omega-3 EE supplements, with a first steep slope of the dose-response curve and a plateau thereafter, with no further beneficial effects on fatal arrhythmic events with higher doses. ${ }^{22}$ Such a hypothesis would explain the high protective effect of omega-3 EE against arrhythmic death in patients with low dietary intake of n-3 PUFA and $\mathrm{HF}^{26}$ or ischemic heart disease. ${ }^{23,29}$

\section{Cardiac hemodynamics}

\section{Cardiac function}

Evidence suggests an improvement of cardiac output with omega-3 EE supplements by means of a positive action on systolic and diastolic function. Experimental evidence of a faster rate of cardiac muscle contraction and relaxation by n-3 PUFA with a consequent positive inotropic effect has been reported. ${ }^{85}$ In addition, EPA and DHA may prevent the myosin heavy chain isoform $\alpha$ to $\beta$ switch, a marker of $\mathrm{HF}$ and left ventricular hypertrophy. ${ }^{86}$

Results of the Cardiovascular Health Study ${ }^{87}$ seem to confirm in older adults the findings previously shown in nonhuman primates ${ }^{88}$ of an association between fish intake and incremental stroke volume due to improvement of early and, possibly, late diastolic filling. Recently, chronic n-3 PUFA administration in athletes has been reported to reduce heart rate and oxygen consumption during exercise without a decrement in performance, in part due to improved energy production and utilization by cardiac myocytes. ${ }^{89}$

Experimental data showed an increase in efficiency of oxygen use by the heart and skeletal muscles after n-3 PUFA supplementation, possibly through improvement in mitochondrial function and efficiency of ATP generation. ${ }^{90,91}$

EPA and DHA was shown to be able to modify mitochondrial membrane properties, activate PPAR, and increase expression of metabolic enzymes, such as those involved in fatty acid oxidation and energy transduction, so 
preventing the increase in left ventricular end-diastolic and end-systolic volumes in a rat model of pressure overload. ${ }^{86}$

\section{Blood pressure}

According to the results of a meta-regression analysis, omega-3 fatty acid administration at a mean dosage of $4100 \mathrm{mg} /$ day was able to decrease mean blood pressure (BP) by $2.3 / 1.5 \mathrm{mmHg} .{ }^{92}$ Subgroup analyses demonstrated that $\mathrm{BP}$ was reduced to a greater extent in older (age $>45$ years) versus younger participants and in hypertensive versus normotensive participants.

The findings of this meta-regression analysis were supported by studies in patients with essential hypertension, ${ }^{47,93}$ hypertriglyceridemia, ${ }^{57}$ or combined hyperlipidemia, ${ }^{44,94}$ patients who had undergone heart transplantation,,$^{95}$ or hypertensive heart transplant recipients, ${ }^{48}$ showing significant reductions in systolic and/or diastolic BP with omega-3 EE given at $2000-6000 \mathrm{mg} /$ day. The reduction of BP may be due to effects on the arterial vascular bed. Improvement of endothelial dysfunction, ${ }^{96}$ reduction of systemic vascular resistance ${ }^{87}$ possibly by induction of nitric oxide production, ${ }^{97}$ reduction of vasoconstrictive response to norepinephrine and angiotensin II, ${ }^{98}$ improvement of arterial wall compliance, ${ }^{99}$ and enhancement of vasodilatory responses ${ }^{98}$ have been reported.

On the other side, some studies reported no evidence of effects of omega-3 EE on BP at doses of $1000 \mathrm{mg} /$ day in post-MI patients, ${ }^{80} 3000 \mathrm{mg} /$ day in patients with mild hypertension, ${ }^{81}$ or $4000 \mathrm{mg} /$ day of omega-3 EE in healthy volunteers. ${ }^{100}$

\section{Endothelial function}

A critical balance between endothelium-derived relaxing and contracting factors maintains vascular homeostasis and vascular smooth muscle tone. The endothelium, by releasing nitric oxide (NO), promotes vasodilatation and inhibits inflammation, thrombosis, and vascular smooth muscle cell proliferation. In addition, NO opposes the actions of potent endothelium-derived contracting factors such as angiotensin-II and endothelin-1 (ET-1). Endothelial dysfunction is a pathologic state in which there is an imbalance in the relative contribution of endothelium-derived relaxing and contracting factors (such as ET-1, angiotensin, and oxidants). Endothelial dysfunction plays an important role in the clinical course of atherosclerosis. Common conditions predisposing to atherosclerosis, such as hypercholesterolemia, hypertension, diabetes, and smoking, are associated with endothelial dysfunction.
A small number of studies found endothelial function to be improved after fish oil ingestion by humans. ${ }^{8}$ In patients with hypercholesterolemia, baseline endothelium-dependent flow-mediated dilatation increased to a significantly greater extent with omega-3 EE $4000 \mathrm{mg} /$ day than with placebo without affecting endothelium-independent dilation. ${ }^{101}$ In a six-week, randomized crossover trial, 20 children with familial (combined) hyperlipidemia received DHA $1200 \mathrm{mg}$ /day. Endothelial function improved in this study, although levels of total cholesterol, LDL, and HDL increased, compared with subjects receiving the National Cholesterol Education Panel (NCEP)-II diet during the control period. ${ }^{102}$ In a randomized, double-blind study comparing $4000 \mathrm{mg}$ /day EPA with $4000 \mathrm{mg}$ /day DHA and with $4000 \mathrm{mg}$ /day olive oil (control) in 59 overweight, mildly hyperlipidemic men, DHA, but not EPA, improved the response to acetylcholine. DHA, however, improved the response to sodium nitroprusside and attenuated the constrictive response to norepinephrine, whilst olive oil had no effect. ${ }^{98}$ More recently, improvements in endothelial function have been reported in patients receiving omega- 3 fatty acids.$^{68}$ Thus the available evidence indicates that EPA-DHA improves endothelial function in patients with CV disorders. When EPA and DHA were compared, only DHA, but not EPA, was found to be effective.

\section{Thrombosis and hemostasis}

In vitro studies have shown that omega- 3 fatty acids have inhibitory effects on thrombosis through reduction of platelet aggregation, ${ }^{103-105}$ and platelet thromboxane B2 response, ${ }^{105}$ thus suggesting a potential cardioprotective effect through antithrombotic mechanisms. ${ }^{21}$ In healthy volunteers receiving omega-3 EE 1000-4000 mg/day, EPA was incorporated into platelets in a dose-dependent manner. ${ }^{43}$

Platelet-activating factor (an inducer of platelet aggregation) was reduced by $900 \mathrm{mg} /$ day EPA given for eight weeks in patients with type 2 diabetes mellitus, the effect being more pronounced after doubling the daily dose. ${ }^{106} \mathrm{In}$ a six-week randomized, double-blind study, $4000 \mathrm{mg} / \mathrm{day}$ of EPA and $4000 \mathrm{mg} /$ day DHA were compared with olive oil in 59 hypertensive type 2 diabetics. DHA, but not EPA, reduced platelet response to collagen and associated thromboxane A2 formation, without differences in other parameters such as fibrinolytic activity. ${ }^{107} \mathrm{In}$ patients with $\mathrm{CAD}$, fibrinolytic activity, as assessed by plasminogen activator inhibitor-I activity levels, was found to be increased by $1800 \mathrm{mg} /$ day of EPA, ${ }^{108}$ and by EPA-DHA $3400 \mathrm{mg} /$ day. ${ }^{109} \mathrm{~A}$ three-month randomized study comparing $850 \mathrm{mg} / \mathrm{EPA}-\mathrm{DHA}$ with usual care in 77 post-MI patients showed no differences in levels of 
fibrinogen or D-dimer, although von Willebrand factor was increased. ${ }^{110}$ Across clinical studies, omega-3 fatty acids did not show a consistent effect on hemostatic variables including levels of fibrinogen, factor VII or VIII or von Willebrand factor. ${ }^{60,111}$ Moreover, changes in levels of fibrinogen, factor VII or VIII, or von Willebrand factor generally did not significantly differ between recipients of 1000-6000 mg/day omega-3 EE and controls in healthy volunteers, ${ }^{112}$ post-MI patients, ${ }^{110}$ patients with mild hypertension, ${ }^{81}$ patients with combined hyperlipidemia ${ }^{109}$ or patients undergoing coronary artery bypass graft (CABG) surgery. ${ }^{113}$

Bleeding time was prolonged in 40 post-MI patients after four weeks of $3400 \mathrm{mg} /$ day EPA-DHA, without significant alteration of other hemostatic parameters, ${ }^{114}$ and increased in one study in CAD patients. ${ }^{115}$ At variance with previous studies, omega-3 EE $6000 \mathrm{mg} /$ day did not affect bleeding time at rest in patients with familial hypercholesterolemia, ${ }^{100,113}$ or in patients undergoing CABG surgery. ${ }^{113}$ In addition, the incidence of bleeding episodes did not significantly differ between omega-3 EE $4000 \mathrm{mg} /$ day and placebo recipients in a large study in patients undergoing CABG surgery who were also receiving warfarin or aspirin. ${ }^{116}$ This finding is reassuring with regard to the current clinical relevance of the concern raised by older studies testing very high omega- 3 fatty acid doses about a potential increased risk of bleeding due to the antithrombotic effect of omega-3 fatty acids. ${ }^{21,117}$

However, hemocoagulatory tests should be performed to monitor adequately patients receiving anticoagulant therapy and the anticoagulant dosage adjusted as necessary. ${ }^{20}$

\section{Atherogenesis and inflammation}

Many effects of n-3 PUFA may positively interfere with atherosclerotic processes. Other than improvement in lipid levels, the effects on cell adhesion molecules, receptor scavenger expression, and vascular smooth muscle cell proliferation may reduce development of atherosclerotic lesions. ${ }^{118}$ Although treatment for six months with omega-3 EE $6000 \mathrm{mg} /$ day did not reduce the incidence of restenosis in patients who had undergone coronary angioplasty, ${ }^{119}$ two meta-analyses suggested that omega-3 fatty acids may indeed prevent restenosis following this procedure. ${ }^{120,121}$ In patients with planned carotid endarterectomy, administration of $2000 \mathrm{mg} /$ day of omega-3 EE significantly increased plaque phospholipid EPA content compared with placebo. ${ }^{78}$ The potential improvement of plaque stability consequent to the increase of EPA and DHA ${ }^{122}$ was based on the finding that plaques from patients receiving omega-3 EE expressed significantly lower mRNA levels for matrix metalloproteinase (MMP)-7, MMP-9, MMP-12, and intercellular adhesion molecule (ICAM)-1 than did plaque from placebo recipients. ${ }^{78}$ Omega-3 EE $4000 \mathrm{mg}$ /day after six weeks' therapy increased soluble E-selectin levels from baseline to a significantly greater extent than did placebo in patients with hypertriglyceridemia. However, after more than six months' treatment, significant decreases in soluble E-selectin levels and in soluble ICAM-1 levels were observed. ${ }^{56}$ Gene expression of platelet-derived growth factors A and B was downregulated in mononuclear cells from healthy volunteers who received omega-3 EE $7000 \mathrm{mg}$ / day for six weeks. ${ }^{123}$ Endotoxin-stimulated tumor necrosis factor- $\alpha$ production in peripheral blood mononuclear cells was significantly reduced from baseline in patients with severe HF who received omega-3 fatty acids $8000 \mathrm{mg} /$ day for 18 weeks. ${ }^{124}$ It has been recently reported that the beneficial effects of n-3 fatty acid supplementation on inflammatory processes may be due to an increase in EPAderived eicosanoids, $\mathrm{PGE}_{3}$ and $\mathrm{LTB}_{5}$, which are less active in the inflammatory response than AA-derived eicosanoids $\left(\mathrm{PGE}_{2}\right.$ and $\left.\mathrm{LTB}_{4}\right){ }^{125}$

At variance with the above, some evidence did not report an improvement of inflammatory markers. C-reactive protein levels were not affected by treatment with omega- 3 fatty acids. ${ }^{60,79}$ Compared with olive oil-treated controls, C-reactive protein, interleukin-6, and tumor necrosis factor- $\alpha$ were unaltered in 59 hypertensive Type 2 diabetics treated for six weeks with $4000 \mathrm{mg}$ / day of EPA or DHA. ${ }^{126}$ In post-MI patients treated with omega-3 EE $1000 \mathrm{mg} /$ day, interleukin-6 levels were not modified to a significant extent compared with controls. ${ }^{10}$ Finally, the effect of n-3 PUFA on oxidative stress remains controversial. ${ }^{118,126,127}$

\section{Clinical efficacy}

\section{After myocardial infarction}

GISSI-Prevenzione was a multicenter, randomized clinical trial that assessed the comparative efficacy of omega-3 EE, as monotherapy or in combination with tocopherol, versus tocopherol monotherapy or control (no treatment) as secondary prevention for post-MI patients. ${ }^{23,128}$ From October 1993 to September 1998, 11,323 patients who had suffered an MI within the previous three months (median 16 days) were randomized to receive omega-3 EE $1000 \mathrm{mg} /$ day $(\mathrm{n}=2835)$, omega-3 EE $1000 \mathrm{mg} / \mathrm{day}+$ tocopherol $300 \mathrm{mg} /$ day $(\mathrm{n}=2830)$, tocopherol $300 \mathrm{mg} /$ day $(\mathrm{n}=2830)$, or control ( $\mathrm{n}=2828$ ) for 42 months. The patients' mean age was 59.4 years, with $16 \%$ aged $>70$ years, and $85.3 \%$ were male. 
At baseline, an ejection fraction of $\leq 30 \%$ and $0.31-0.40$ was present in $2.6 \%$ and $11.1 \%$ of patients, respectively; $42.4 \%$ of patients were smokers, $35.6 \%$ were diagnosed with arterial hypertension, $4.4 \%$ had claudication, $14.8 \%$ had diabetes mellitus, $19.3 \%$ had ventricular arrhythmias, and 28.9\% had a positive exercise stress test. Mediterranean dietary advices were given to all patients. Investigators were required to prescribe post-MI evidence-based therapy at baseline as well during the course of the study. At baseline, ACE inhibitors, antiplatelet agents, $\beta$-blockers, and lipid-lowering drugs were prescribed to $46.9 \%, 91.7 \%, 44.3 \%$, and $4.7 \%$ of patients, respectively. The proportion of patients receiving the aforementioned medical treatments did not change much during the course of the study, but lipid-lowering treatments were prescribed to more than $30 \%$ of patients after six months and, at the end of the study, approximately $50 \%$ of patients was treated with statins.

The primary combined efficacy endpoints for the GISSI-Prevenzione study were the cumulative rate of all-cause death, nonfatal MI, and nonfatal stroke, and the cumulative rates of $\mathrm{CV}$ death, nonfatal MI, and nonfatal stroke. Secondary endpoints included the individual components of the primary endpoints and the major causes of death.

The efficacy of the experimental treatments was compared by two prespecified intention-to-treat analyses over 42 months of follow-up. A four-way analysis of data compared the efficacy of omega-3 EE monotherapy, tocopherol monotherapy, and omega-3 EE + tocopherol with that of the control over the same time period; the efficacy of omega-3 EE + tocopherol was also compared with omega-3 EE monotherapy and tocopherol monotherapy. A two-way factorial analysis compared omega-3 EE-based therapy (omega-3 EE monotherapy and omega-3 EE + tocopherol groups) with that of non-omega-3 EE-based therapy (tocopherol monotherapy and control groups) and the efficacy of tocopherol-based therapy (tocopherol monotherapy and omega-3 EE + tocopherol groups) versus non-tocopherol-based therapy (omega-3 EE monotherapy and control).

The results of GISSI-Prevenzione showed that omega-3 EE had a secondary preventive effect in patients with recent MI. The full efficacy profile of omega-3 EE is summarized in Table 1.

In the four-way analysis there were significant reductions of both coprimary endpoints, ie, a $16 \%$ relative risk decrease for the combined endpoint of death, nonfatal MI, and nonfatal stroke (95\% CI 3-27, $P=0.02)$ and a $20 \%$ relative risk decrease for the secondary combined endpoint of $\mathrm{CV}$ death, nonfatal $\mathrm{MI}$, and nonfatal stroke (95\% CI 6-32, $P=0.006$ ). Analyses of the individual components of the main endpoint were instrumental in speculation as to the mechanism of action of omega-3 EE. Almost all the benefit obtained with omega-3 EE in the combined endpoint was due to the decrease in fatal events ( $-21 \%$ of total deaths, $-30 \%$ of CV deaths, and $-44 \%$ of sudden deaths), suggesting that antiarrhythmic effect is the probable mechanism of action of omega-3 EE. With regard to nonfatal $\mathrm{CV}$ events, there was no significant difference between the treatment groups, and the results for the combined treatment compared with controls on the primary combined endpoint and on total mortality were consistent with those obtained with omega-3 EE alone. No increased benefit was apparent when the rate of the combined endpoint of death, nonfatal MI and nonfatal stroke among patients receiving omega-3 EE + vitamin E was compared with that of the group receiving omega-3 EE alone or with that of patients treated with vitamin E alone. Patients receiving vitamin $\mathrm{E}$ and controls did not differ significantly when data were analyzed for the combined endpoint as well as for its individual components. Treatment with omega-3 EE alone significantly lowered the risk of total CHD events (0.78 [0.65-0.94], $P=0.008)$, whereas the reduction of risk observed with vitamin $E$ was not statistically significant. No change in fatal + nonfatal stroke was found for any tested treatment. The results of the two-way analysis adjusted for interaction between the treatments were exactly the same as the results of the four-way analyses, with the interaction being statistically significant for $\mathrm{CV}$, cardiac, and sudden death, and statistically relevant $(P<0.10)$ for the second main endpoint and all CHD events (Table 1).

At six months, a significant reduction in TG levels was observed, but no clinically relevant change from baseline was shown for total cholesterol, LDL-C and HDL-C levels, fibrinogen, and glycemia.

A post hoc analysis of GISSI-Prevenzione ${ }^{29}$ assessed the time course of the benefit of omega-3 EE on mortality and supported the hypothesis of an antiarrhythmic effect of omega-3 EE. Survival curves for n-3 PUFA treatment diverged early after randomization, and total mortality was significantly lowered after only three months of treatment (RR 0.59; 95\% CI 0.36-0.97; $P=0.037$ ). The reduction in risk of sudden death was specifically relevant and statistically significant already at four months (RR 0.47; 95\% CI $0.219-0.995 ; P=0.048)$. A similarly significant, although delayed, pattern after six to eight months of treatment was observed for $\mathrm{CV}$, cardiac, and coronary deaths. 


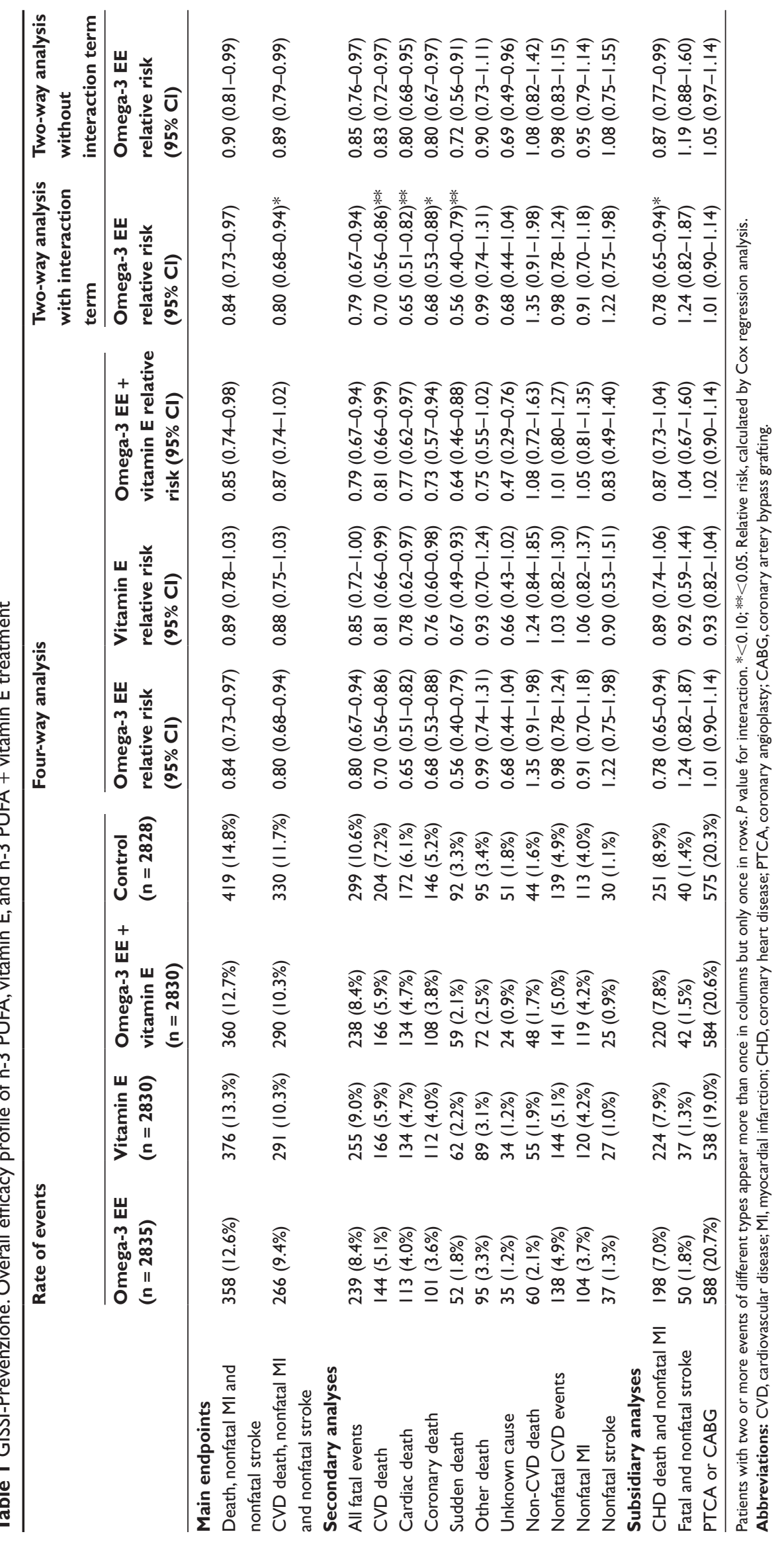


Another post hoc analysis ${ }^{31}$ of the GISSI-Prevenzione study reported that treatment with omega-3 EE was effective both in patients with and without left ventricular dysfunction (LVEF $>50 \%$ ) with an increase of benefit in those with left ventricular dysfunction, in whom omega-EE appeared more effective in reducing sudden death.

More recently, the randomized, double-blind, placebocontrolled, multicenter OMEGA study evaluated the effect of omega-3 EE $1 \mathrm{~g}$ /day on the rate of sudden cardiac death in patients with $\mathrm{MI}$ in the previous 3-14 days, with a 12-month follow-up. Secondary endpoints included total mortality, reinfarction, revascularization, rhythm abnormalities in Holter monitoring, and stroke. ${ }^{129,130} \mathrm{~A}$ total of 3851 patients were included in the study, $74.4 \%$ were male and $25.6 \%$ female; $24.1 \%$ and $75.9 \%$ had a LVEF $<0.45$ and $\geq 0.45$, respectively; $27.0 \%$ were diabetics and $1.8 \%$ had renal failure. With regard to pharmacologic treatments at baseline, $69.5 \%$ of patients were receiving an ACE inhibitor, $<94 \%$ an antiplatelet agent, $85.7 \%$ a $\beta$-blocker, and $81.5 \%$ were receiving statins. Data were reported for per protocol populations. Preliminary data showed no significant difference in the incidence of sudden cardiac death between omega-3 EE (1.5\%) and placebo (1.5\%) groups, neither with regard to the secondary endpoints, including total mortality $(4.6 \%$ versus $3.7 \%$ ), reinfarction ( $4.5 \%$ versus $4.1 \%$ ), revascularization $(27.7 \%$ versus $29.1 \%)$, arrhythmic events $(1.1 \%$ versus $0.7 \%$ ), and stroke (1.4 versus $0.7 \%$ ). However the OMEGA study was designed assuming a sudden cardiac death rate of $1.9 \%$ in omega-3 EE recipients and $3.5 \%$ in placebo recipients, whilst the observed incidence was definitely lower (1.5\% in both groups), thus making the trial heavily underpowered. ${ }^{130}$

\section{Heart failure}

Several observational and clinical studies have reported an association between fish consumption and reduced risk of $\mathrm{HF}^{30,32,33,131}$ As already reported above, a post hoc analysis ${ }^{31}$ of the GISSI-Prevenzione study ${ }^{23}$ indicated that treatment with $1 \mathrm{~g}$ /day of omega-3 EE had similar beneficial effects on total mortality in patients with (LVEF $\leq 50 \%$, RR 0.76 ; $0.60-0.96, P=0.02$ ) and without left ventricular dysfunction (LVEF $>50 \%$, RR $0.81 ; 0.59-1.10, P=0.17$ ). Moreover, the treatment appeared more effective in reducing sudden cardiac death in patients than those without left ventricular dysfunction.

Recently, the results of the GISSI-HF study, a randomized, placebo-controlled, multicenter trial investigating the efficacy of omega-3 EE in chronic HF were published. ${ }^{26}$
A total of 6975 patients aged 18 years or older, with clinical evidence of HF of any cause and New York Heart Association (NYHA) Class II-IV were randomized to $850-882 \mathrm{mg}$ EPA-DHA daily as EE or matching placebo, and followed for a median of 3.9 years. Healthy lifestyle advice and evidence-based medical therapy for HF were positively recommended to all participants. The mean age of the patients was 67 years (SD \pm 11$), 2947$ (42\%) were older than 70 years, and 1516 (22\%) were women. At baseline, 4425 (63\%), 2365 (34\%), and $185(3 \%)$ were in NYHA Class II, III, and IV, respectively; $653(9 \%)$ had a LVEF $>40 \%$; 987 (14\%) were smokers, 3809 (55\%) had hypertension, 1974 (28\%) diabetes mellitus, 610 (9\%) peripheral vascular disease, and 256 (4\%) neoplasia. With regard to medical history, 2909 (42\%) had had an MI, 2137 (31\%) a coronary revascularization, and 497 (4\%) an ICD. Cause of HF was ischemic in 3467 (50\%) patients, dilatative in $2025(29 \%)$, hypertensive in $1036(15 \%)$, and other or unknown in 447 (6\%). At study admission, recommended medical therapy for HF was widely used: 6520 (93\%) patients were being treated with blockers of the renin-angiotensin system, 4522 (65\%) with $\beta$-blockers, 2740 (39\%) with spironolactone, $6260(90 \%)$ with diuretics, and $4074(58 \%)$ with antiplatelet agents.

Statistically significant risk reductions in the two coprimary endpoints were observed in patients treated with omega-3 EE, ie, $9 \%$ and $8 \%$ for mortality and mortality + admission to hospital for a $\mathrm{CV}$ reason, respectively (Table 2). Main study results were consistent with those of the secondary analyses which were predefined in the study protocol, namely baseline characteristics, secondary outcomes, and per protocol analysis in the 4994 who were compliant with experimental treatments (Table 2). Worsening of HF and presumed arrhythmic death accounted for $62 \%$ of all deaths and were lower in the omega-3 EE group than in the placebo group. Almost half of the absolute reduction of risk that was attributable to treatment was due to the reduction of ventricular arrhythmias (mortality, $0.9 \%$ of $1.8 \%$; first CV hospitalization, $1.0 \%$ of $1.7 \%$ ). Because of the high mortality and hospitalization rates in HF patients, the apparently modest relative risk reduction due to omega-3 EE can be translated into an absolute benefit of 18 avoided deaths and 17 prevented CV hospitalizations for every 1000 patients treated for 3.9 years with omega-3 EE. In addition, the benefit in both coprimary endpoints (mortality and hospitalization) suggests that omega-3 EE might also positively affect the pathophysiologic mechanisms leading to the progression of HF. 
Table 2 GISSI-HF primary outcomes, secondary outcomes, and causes of death

\begin{tabular}{|c|c|c|c|c|}
\hline & $\begin{array}{l}n-3 \text { PUFA } \\
(n=3494)\end{array}$ & $\begin{array}{l}\text { Placebo } \\
(n=348 I)\end{array}$ & $\begin{array}{l}\text { Adjusted HR } \\
(95 \% \mathrm{Cl}) *\end{array}$ & $P$ value \\
\hline \multicolumn{5}{|l|}{ Primary outcomes } \\
\hline \multirow{2}{*}{ Deaths from any cause } & 955 & 1014 & $0.91(0.833-0.998)$ & 0.041 \\
\hline & $(27.3 \%)$ & $(29.1 \%)$ & & \\
\hline Deaths from any cause or admitted & $\mid 981$ & 2053 & $0.92(0.849-0.999)$ & 0.009 \\
\hline in hospital for $\mathrm{CV}$ reasons & $(56.7 \%)$ & $(58.9 \%)$ & & \\
\hline \multicolumn{5}{|l|}{ Secondary outcomes } \\
\hline \multirow[t]{2}{*}{ Deaths from a CV cause } & 712 & 765 & $0.90(0.81-0.99)$ & 0.045 \\
\hline & $(20.4 \%)$ & $(22.0 \%)$ & & \\
\hline \multirow[t]{2}{*}{ Patients who had a SCD } & 307 & 325 & $0.93(0.79-1.08)$ & 0.333 \\
\hline & $(8.8 \%)$ & $(9.3 \%)$ & & \\
\hline \multirow[t]{2}{*}{ Patient admissions: } & 1986 & 2028 & $0.94(0.88-1.00)$ & 0.049 \\
\hline & $(56.8 \%)$ & $(58.3 \%)$ & & \\
\hline \multirow[t]{2}{*}{ For a CV reason } & 1635 & 1687 & $0.93(0.87-0.99)$ & 0.026 \\
\hline & $(46.8 \%)$ & $(48.5 \%)$ & & \\
\hline \multirow[t]{2}{*}{ For HF } & 978 & 995 & $0.94(0.86-1.02)$ & 0.147 \\
\hline & $(28.0 \%)$ & $(28.6 \%)$ & & \\
\hline Deaths from a CV cause or admitted & 2157 & 2202 & $0.94(0.89-0.99)$ & 0.043 \\
\hline for any reason & $(61.7 \%)$ & $(63.3 \%)$ & & \\
\hline \multirow[t]{2}{*}{ Patients with fatal and nonfatal MI } & 107 & 129 & $0.82(0.63-1.06)$ & 0.121 \\
\hline & $(3.1 \%)$ & $(3.7 \%)$ & & \\
\hline \multirow[t]{2}{*}{ Patients with fatal and nonfatal stroke } & 122 & 103 & $1.16(0.89-1.5 \mathrm{I})$ & 0.271 \\
\hline & $(3.5 \%)$ & $(3.0 \%)$ & & \\
\hline \multicolumn{5}{|l|}{ Causes of death } \\
\hline \multirow[t]{2}{*}{ Acute MI } & 20 & 25 & $0.77(0.43-1.39)$ & 0.382 \\
\hline & $(0.6 \%)$ & $(0.7 \%)$ & & \\
\hline \multirow[t]{2}{*}{ Worsening HF } & 319 & 332 & $0.92(0.79-1.07)$ & 0.275 \\
\hline & $(9.1 \%)$ & $(9.5 \%)$ & & \\
\hline \multirow{2}{*}{ Presumed arrhythmic } & 274 & 304 & $0.88(0.75-1.04)$ & 0.141 \\
\hline & $(7.8 \%)$ & $(8.7 \%)$ & & \\
\hline
\end{tabular}

Notes: $* 95 \% \mathrm{Cl}$ was calculated with a Cox proportional hazards model with adjustment for admission to hospital for heart failure in the preceding year, previous pacemaker, and aortic stenosis. Data are number (\%) unless otherwise stated.

Abbreviations: $\mathrm{Cl}$, confidence interval; CV, cardiovascular; HF, heart failure; HR, hazards ratio; MI, myocardial infarction; PUFA, polyunsaturated fatty acids; SCD, sudden cardiac death.

\section{Safety and tolerability}

In general, omega-3 EE is safe and well tolerated. In hypertriglyceridemic patients receiving omega-3 EE, either alone or in combination with simvastatin, levels of hematocrit, hemoglobin, fasting blood glucose, HbAlc, creatinine, alanine transferase (ALT), aspartate transaminase (AST), creatine phosphokinase, fibrinogen, fructosamine, homocysteine, and uric acid were not altered to a clinically significant extent. ${ }^{45,46,132}$

However, in recipients of omega-3 EE + simvastatin $40 \mathrm{mg} /$ day, a mild clinically insignificant elevation in ALT, AST, and fasting glucose levels occurred more frequently than in placebo + simvastatin $40 \mathrm{mg} /$ day recipients. ${ }^{132}$

With regard to safety and tolerability in post-MI patients, data from GISSI-Prevenzione ${ }^{23,133}$ are reported here (the results from OMEGA trial are not yet fully available). In $4.9 \%$ and $1.4 \%$ of patients receiving omega-3 EE $(1000 \mathrm{mg} /$ day)-based therapy and in $2.9 \%$ and $0.4 \%$ of patients receiving tocopherol (300 $\mathrm{mg} /$ day)-based therapy, treatment-emergent gastrointestinal disturbances and nausea were observed. Cancer developed in $2.7 \%$ of patients receiving omega-3 EE alone, $2.3 \%$ of those receiving omega-3 EE + tocopherol, $2.6 \%$ of those receiving both, and $2.2 \%$ of control group; $1.5 \%, 0.9 \%, 1.2 \%$, and $1.2 \%$ of patients, respectively, developed nonfatal cancer. Therapy was discontinued by $11.6 \%$ of patients receiving omega-3 EE versus $7.3 \%$ of patients receiving tocopherol at 12 months while, at 42 months $28.5 \%$ versus $26.2 \%$ of patients discontinued therapy, respectively. Adverse events leading to permanent discontinuation of therapy occurred in $3.8 \%$ of patients receiving omega- $3 \mathrm{EE}$ and $2.1 \%$ of patients receiving tocopherol.

Amongst the 6975 HF patients in the GISSI-HF trial, $28.7 \%$ of those allocated to omega-3 EE and $29.6 \%$ of those receiving placebo were no longer taking the study drug for various reasons. An adverse drug reaction was the cause of permanent discontinuation in $2.9 \%$ of omega- $3 \mathrm{EE}$ recipients and $3.0 \%$ of placebo recipients, with gastrointestinal disor- 
ders being the most frequent cause in both groups $(2.7 \%$ and $2.6 \%$, respectively). ${ }^{26}$

Available evidence indicates that oral administration of $1000 \mathrm{mg}$ omega-3 EE is generally well tolerated. Indeed, treatment-emergent adverse events associated with omega-3 EE both in patients with hypertriglyceridemia and in more fragile populations, including patients with a previous MI or with HF, were generally gastrointestinal in nature and minor in intensity.

\section{Conclusion}

CVD results from the interaction of multiple risk factors. Therefore, the major cardiology societies provide a number of recommendations aimed at controlling these risk factors in their programs for CVD prevention. ${ }^{36,134}$ The first step in all programs for CVD prevention is lifestyle modification aimed at avoiding physical inactivity, an unhealthy diet, smoking, and overweight/obesity. The presence of a high level of risk or the failure of lifestyle modification warrants utilization of drug therapy.

The National Cholesterol Education Program Adult Treatment Panel III has identified elevated LDL-C levels as a major risk factor for CHD, and these are the primary target for lipid-lowering therapy. Elevated TG levels have also been identified recently as an independent risk factor for CHD. ${ }^{135}$ Oral omega-3 EE, alone or in combination with simvastatin or atorvastatin, was generally effective as an adjunct to diet in the treatment of hypertriglyceridemia in adult patients. Available evidence indicates that omega-3 EE given at 3-4 grams per day significantly reduced TG levels, and significantly increased HDL-C levels compared with placebo.

The results of GISSI-Prevenzione demonstrated that oral administration of omega-3 EE $1000 \mathrm{mg} /$ day was generally effective as an adjuvant therapy to standard treatment (eg, ACE inhibitors, antiplatelet agents, $\beta$-blockers, statins) for secondary prevention in post-MI adult patients. Indeed, omega-3 EE-based therapy significantly reduced the risk of the primary composite endpoint of death + nonfatal MI + nonfatal stroke $(-16 \%)$ as well as various secondary endpoints (including death, $\mathrm{CV}$ death, and sudden death). The reduction in the risk of the coprimary composite efficacy endpoints, can be translated into an absolute benefit of four lives saved every 1000 post-MI patients treated with omega-3 EE for one year (Figure 2). The observed reduction of fatal events, especially of sudden death ( -2 events) contributed to the significant reductions in the risk of the coprimary composite efficacy endpoints.

\section{DEATH}

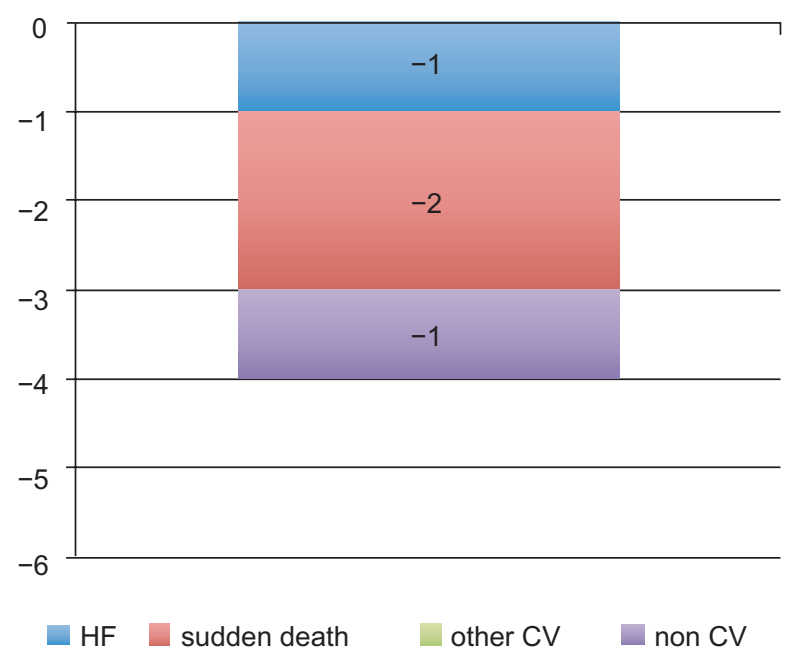

Figure 2 GISSI-Prevenzione study: Number of lives saved in every 1000 post-MI patients treated with omega-3 EE $1000 \mathrm{mg} /$ day for one year.

Abbreviations: CV, cardiovascular; EE, ethyl esters; MI, myocardial infarction.

The results of GISSI-HF showed that the administration of omega-3 EE (850-882 mg daily) in patients with chronic HF who were already receiving recommended medical therapy was effective in reducing the coprimary efficacy endpoints of all-cause mortality $(-19 \%)$ and all-cause mortality or hospitalizations for $\mathrm{CV}$ reasons $(-18 \%)$. These risk reduction can be translated into an absolute benefit of five lives saved every $1000 \mathrm{HF}$ patients treated with omega-3 EE for one year (Figure 3). The treatment also avoided four hospital admissions for $\mathrm{CV}$ reasons. As in GISSI-Prevenzione, ${ }^{23}$ the main benefit appeared to be a reduction of arrhythmic events ( -2 sudden deaths and -3 hospital admissions for ventricular arrhythmias, Figure 3).

The precise mechanisms of action of omega-3 EE are not yet fully understood. Findings from the GISSI studies

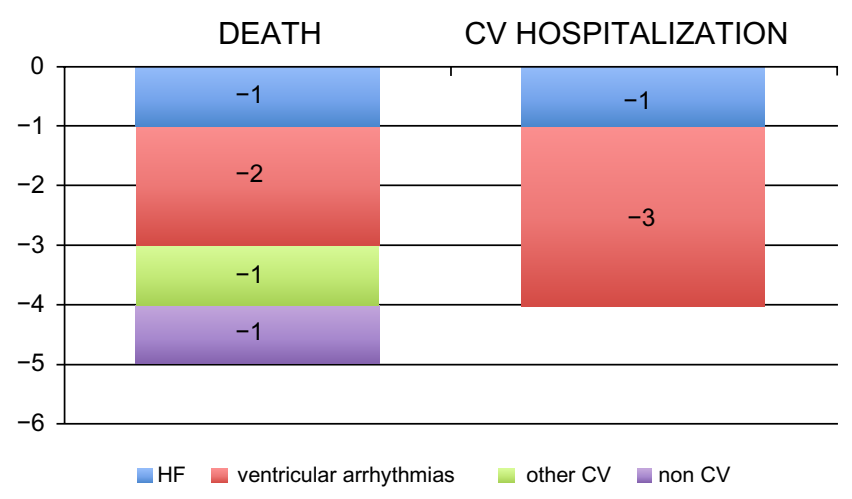

Figure 3 GISSI-HF study: Number of events avoided every 1000 HF patients treated with omega-3 EE $1000 \mathrm{mg} /$ day for one year.

Abbreviations: CV, cardiovascular; EE, ethyl esters; MI, myocardial infarction. 
suggest that the major component of the observed benefit is an antiarrhythmic effect. This hypothesis appears to be supported by previous evidence from various sources, including epidemiologic studies examining fish consumption and preclinical studies. Other factors that have been hypothesized to contribute to the cardioprotective effects of omega-3 fatty acids include effects on hemodynamics, lipid levels, endothelial function, thrombosis and hemostasis, atherogenesis, and inflammation.

According to the available evidence, the American Heart Association/American College of Cardiology, the European Society for Cardiology, and a number of national cardiac societies recommend the intake of $1 \mathrm{~g} /$ day of the two marine omega-3 fatty acids, EPA and DHA, for secondary prevention, $\mathrm{CV}$ prevention, treatment post-MI, and prevention of sudden cardiac death. ${ }^{35,134,136-138}$

To date, in the various European countries, oral omega-3 EE (1000 mg/day) is indicated as a component of standard treatment for secondary prevention in post-MI patients, which includes ACE inhibitors, antiplatelet agents, $\beta$-blockers, and statins. ${ }^{20,42}$ It is also indicated for use alone (2000-4000 mg/day) or in combination with statins, as an adjunct to diet in the treatment of hypertriglyceridemia in adult patients who have not responded to dietary measures..$^{20,42}$ In the US, omega-3 EE is indicated as an adjunct to diet in the treatment of hypertriglyceridemia in adult patients. ${ }^{20,42}$

The recent results of GISSI-HF demonstrating a clinical benefit in patients with HF will probably be followed by the incorporation of omega-3 EE in the next guidelines for these patients. Indeed, despite available treatments which significantly decreased the per-year mortality in the "artificial scenario" of clinical trials, the risk of death in patients with HF remains too high in clinical practice.

Undoubtedly further studies are needed to determine the optimal dose as well as the effects of the various doses in different populations, and to clarify whether the more important mechanism for clinical benefit is the antiarrhythmic effect of omega-3 EE.

\section{Disclosure}

The authors report no conflicts of interest in this work.

\section{References}

1. Bang HO, Dyerberg J. Plasma lipids and lipoproteins in Greenlandic west coast Eskimos. Acta Med Scand. 1972;192(1-2):85-94.

2. Bang HO, Dyerberg J, Nielsen AB. Plasma lipid and lipoprotein pattern in Greenlandic West-coast Eskimos. Lancet. 1971;1(7710): $1143-1145$
3. Bersot T, Haffner S, Harris WS, Kellick KA, Morris CM. Hypertriglyceridemia: Management of atherogenic dyslipidemia. J Fam Pract. 2006;55(7):S1-S8.

4. Kris-Etherton PM, Harris WS, Appel LJ. Fish consumption, fish oil, omega-3 fatty acids, and cardiovascular disease. Circulation. 2002;106(21):2747-2757.

5. Kris-Etherton PM, Harris WS, Appel LJ. Omega-3 fatty acids and cardiovascular disease: New recommendations from the American Heart Association. Arterioscler Thromb Vasc Biol. 2003;23(2): 151-152.

6. Psota TL, Gebauer SK, Kris-Etherton P. Dietary omega-3 fatty acid intake and cardiovascular risk. Am J Cardiol. 2006;98(4A):3i-18i.

7. Thompson GR. Management of dyslipidaemia. Heart. 2004;90(8): 949-955.

8. von Schacky C. The role of omega-3 fatty acids in cardiovascular disease. Curr Atheroscler Rep. 2003;5(2):139-145.

9. von Schacky C. Prophylaxis of atherosclerosis with marine omega3 fatty acids. A comprehensive strategy. Ann Intern Med. 1987; 107(6):890-899.

10. Castelli WP. Cholesterol and lipids in the risk of coronary artery diseasethe Framingham Heart Study. Can J Cardiol. 1988;4 Suppl A:5A-10A.

11. Assmann G, Schulte H. Relation of high-density lipoprotein cholesterol and triglycerides to incidence of atherosclerotic coronary artery disease (the PROCAM experience). Prospective Cardiovascular Munster study. Am J Cardiol. 1992;70(7):733-737.

12. Miller M, Cannon CP, Murphy SA, Qin J, Ray KK, Braunwald E. Impact of triglyceride levels beyond low-density lipoprotein cholesterol after acute coronary syndrome in the PROVE IT-TIMI 22 trial. $J$ Am Coll Cardiol. 2008;51(7):724-730.

13. Miller M, Seidler A, Moalemi A, Pearson TA. Normal triglyceride levels and coronary artery disease events: The Baltimore Coronary Observational Long-Term Study. J Am Coll Cardiol. 1998;31(6): 1252-1257.

14. Austin MA, King MC, Vranizan KM, Krauss RM. Atherogenic lipoprotein phenotype. A proposed genetic marker for coronary heart disease risk. Circulation. 1990;82(2):495-506.

15. Manninen V, Tenkanen L, Koskinen P, et al. Joint effects of serum triglyceride and LDL cholesterol and HDL cholesterol concentrations on coronary heart disease risk in the Helsinki Heart Study. Implications for treatment. Circulation. 1992;85(1):37-45.

16. Goldbourt U, Brunner D, Behar S, Reicher-Reiss H. Baseline characteristics of patients participating in the Bezafibrate Infarction Prevention (BIP) Study. Eur Heart J. 1998;19 Suppl H:H42-H47.

17. Miller M. Differentiating the effects of raising low levels of highdensity lipoprotein cholesterol versus lowering normal triglycerides: Further insights from the Veterans Affairs High-Density Lipoprotein Intervention Trial. Am J Cardiol. 2000;86(12A):23L-27L.

18. Rubins HB, Robins SJ, Collins D, et al. Gemfibrozil for the secondary prevention of coronary heart disease in men with low levels of high-density lipoprotein cholesterol. Veterans Affairs High-Density Lipoprotein Cholesterol Intervention Trial Study Group. N Engl J Med. 1999;341(6):410-418.

19. von Schacky C. A review of omega-3 ethyl esters for cardiovascular prevention and treatment of increased blood triglyceride levels. Vasc Health Risk Manag. 2006;2(3):251-262.

20. Solvay Healthcare Limited. Omacor: Summary of product characteristics. Available at: http://emc.medicines.org.uk/medicine/10312/SPC/ Omacor/. Accessed August 11, 2009.

21. Bays HE. Safety considerations with omega-3 fatty acid therapy. Am J Cardiol. 2007;99(6A):35C-43C.

22. Mozaffarian D, Rimm EB. Fish intake, contaminants, and human health: Evaluating the risks and the benefits. JAMA. 2006;296(15): 1885-1889.

23. Dietary supplementation with $n-3$ polyunsaturated fatty acids and vitamin E after myocardial infarction: Results of the GISSI-Prevenzione trial. Gruppo Italiano per lo Studio della Sopravvivenza nell'Infarto miocardico. Lancet. 1999;354(9177):447-455. 
24. Hoy SM, Keating GM. Omega-3 ethylester concentrate: A review of its use in secondary prevention post-myocardial infarction and the treatment of hypertriglyceridaemia. Drugs. 2009;69(8):1077-1105.

25. Lee JH, O'Keefe JH, Lavie CJ, Marchioli R, Harris WS. Omega-3 fatty acids for cardioprotection. Mayo Clin Proc. 2008;83(3):324-332.

26. Tavazzi L, Maggioni AP, Marchioli R, et al. Effect of n-3 polyunsaturated fatty acids in patients with chronic heart failure (the GISSI-HF trial): A randomised, double-blind, placebo-controlled trial. Lancet. 2008;372(9645):1223-1230.

27. von Schacky C, Harris WS. Cardiovascular benefits of omega-3 fatty acids. Cardiovasc Res. 2007;73(2):310-315.

28. Harris WS, Poston WC, Haddock CK. Tissue n-3 and n-6 fatty acids and risk for coronary heart disease events. Atherosclerosis. 2007; 193(1):1-10

29. Marchioli R, Barzi F, Bomba E, et al. Early protection against sudden death by n-3 polyunsaturated fatty acids after myocardial infarction: Time-course analysis of the results of the Gruppo Italiano per lo Studio della Sopravvivenza nell'Infarto Miocardico (GISSI)-Prevenzione. Circulation. 2002;105(16):1897-1903.

30. Levitan EB, Wolk A, Mittleman MA. Fish consumption, marine omega-3 fatty acids, and incidence of heart failure: A populationbased prospective study of middle-aged and elderly men. Eur Heart J. 2009;30(12):1495-1500.

31. Macchia A, Levantesi G, Franzosi MG, et al. Left ventricular systolic dysfunction, total mortality, and sudden death in patients with myocardial infarction treated with n-3 polyunsaturated fatty acids. Eur $J$ Heart Fail. 2005;7(5):904-909.

32. Mozaffarian D, Bryson CL, Lemaitre RN, Burke GL, Siscovick DS. Fish intake and risk of incident heart failure. $\mathrm{J} \mathrm{Am} \mathrm{Coll} \mathrm{Cardiol.}$ 2005;45(12):2015-2021

33. Yamagishi K, Nettleton JA, Folsom AR. Plasma fatty acid composition and incident heart failure in middle-aged adults: The Atherosclerosis Risk in Communities (ARIC) Study. Am Heart J. 2008;156(5): 965-974

34. Hooper L, Thompson RL, Harrison RA, et al. Omega 3 fatty acids for prevention and treatment of cardiovascular disease. Cochrane Database Syst Rev. 2004(4):CD003177.

35. Hooper L, Thompson RL, Harrison RA, et al. Risks and benefits of omega 3 fats for mortality, cardiovascular disease, and cancer: Systematic review. BMJ. 2006;332(7544):752-760.

36. Graham I, Atar D, Borch-Johnsen K, et al. European guidelines on cardiovascular disease prevention in clinical practice: Executive summary. Fourth Joint Task Force of the European Society of Cardiology and other societies on cardiovascular disease prevention in clinical practice (constituted by representatives of nine societies and by invited experts). Eur J Cardiovasc Prev Rehabil. 2007;14 Suppl 2:E1-E40.

37. von Schacky C, Harris WS, Mozaffarian D, Kris-Etherton PM. Response to Hoopers et al. Cochrane Review. Available at: http://www. issfal.org.uk/response-to-hoopers-et-al-cochrane-review.html. Accessed 2009 September 16.

38. Leon H, Shibata MC, Sivakumaran S, Dorgan M, Chatterley T, Tsuyuki RT. Effect of fish oil on arrhythmias and mortality: Systematic review. BMJ. 2008;337:a2931.

39. Wang C, Harris WS, Chung M, et al. n-3 Fatty acids from fish or fish-oil supplements, but not alpha-linolenic acid, benefit cardiovascular disease outcomes in primary and secondary prevention studies: A systematic review. Am J Clin Nutr. 2006;84(1):5-17.

40. Bryhn M, Hansteen H, Schanche T, Aakre SE. The bioavailability and pharmacodynamics of different concentrations of omega-3 acid ethyl esters. Prostaglandins Leukot Essent Fatty Acids. 2006;75(1):19-24.

41. Nordoy A, Barstad L, Connor WE, Hatcher L. Absorption of the n-3 eicosapentaenoic and docosahexaenoic acids as ethyl esters and triglycerides by humans. Am J Clin Nutr. 1991;53(5):1185-1890.

42. Reliant Pharmaceuticals. Lovaza prescribing information. Available at: http://www.accessdata.fda.gov/drugsatfda_docs/1abel/2009/ 021654s023lbl.pdf Accessed 2009 August 11.
43. Di Stasi D, Bernasconi R, Marchioli R, et al. Early modifications of fatty acid composition in plasma phospholipids, platelets and mononucleates of healthy volunteers after low doses of n-3 polyunsaturated fatty acids. Eur J Clin Pharmacol. 2004;60(3):183-190.

44. Grundt H, Nilsen DW, Hetland O, et al. Improvement of serum lipids and blood pressure during intervention with n-3 fatty acids was not associated with changes in insulin levels in subjects with combined hyperlipidaemia. J Intern Med. 1995;237(3):249-259.

45. Harris WS, Ginsberg HN, Arunakul N, et al. Safety and efficacy of Omacor in severe hypertriglyceridemia. J Cardiovasc Risk. 1997;4(5-6): 385-391.

46. Durrington PN, Bhatnagar D, Mackness MI, et al. An omega-3 polyunsaturated fatty acid concentrate administered for one year decreased triglycerides in simvastatin treated patients with coronary heart disease and persisting hypertriglyceridaemia. Heart. 2001;85(5): 544-548.

47. Toft I, Bonaa KH, Ingebretsen OC, Nordoy A, Jenssen T. Effects of n-3 polyunsaturated fatty acids on glucose homeostasis and blood pressure in essential hypertension. A randomized, controlled trial. Ann Intern Med. 1995;123(12):911-918.

48. Holm T, Andreassen AK, Aukrust P, et al. Omega-3 fatty acids improve blood pressure control and preserve renal function in hypertensive heart transplant recipients. Eur Heart J. 2001;22(5):428-436.

49. Calder PC. Omega 3 polyunsaturated fatty acids, inflammation and immunity. World Rev Nutr Diet. 2001;88:109-116.

50. Di Spirito M, Morelli G, Doyle RT, Johnson J, McKenney J. Effect of omega-3-acid ethyl esters on steady-state plasma pharmacokinetics of atorvastatin in healthy adults. Expert Opin Pharmacother. 2008;9(17):2939-2945.

51. Gosai P, Liu J, Doyle RT, et al. Effect of omega-3-acid ethyl esters on the steady-state plasma pharmacokinetics of rosuvastatin in healthy adults. Expert Opin Pharmacother. 2008;9(17):2947-2953.

52. McKenney JM, Swearingen D, Di Spirito M, et al. Study of the pharmacokinetic interaction between simvastatin and prescription omega3-acid ethyl esters. J Clin Pharmacol. 2006;46(7):785-791.

53. Mori TA, Woodman RJ. The independent effects of eicosapentaenoic acid and docosahexaenoic acid on cardiovascular risk factors in humans. Curr Opin Clin Nutr Metab Care. 2006;9(2):95-104.

54. Maki KC, McKenney JM, Reeves MS, Lubin BC, Dicklin MR. Effects of adding prescription omega-3 acid ethyl esters to simvastatin $(20 \mathrm{mg} /$ day) on lipids and lipoprotein particles in men and women with mixed dyslipidemia. Am J Cardiol. 2008;102(4):429-433.

55. Calabresi L, Donati D, Pazzucconi F, Sirtori CR, Franceschini G. Omacor in familial combined hyperlipidemia: Effects on lipids and low density lipoprotein subclasses. Atherosclerosis. 2000;148(2):387-396.

56. Abe Y, El-Masri B, Kimball KT, et al. Soluble cell adhesion molecules in hypertriglyceridemia and potential significance on monocyte adhesion. Arterioscler Thromb Vasc Biol. 1998;18(5):723-731.

57. Mackness MI, Bhatnagar D, Durrington PN, et al. Effects of a new fish oil concentrate on plasma lipids and lipoproteins in patients with hypertriglyceridaemia. Eur J Clin Nutr. 1994;48(12):859-865.

58. Pownall HJ, Brauchi D, Kilinc C, et al. Correlation of serum triglyceride and its reduction by omega-3 fatty acids with lipid transfer activity and the neutral lipid compositions of high-density and low-density lipoproteins. Atherosclerosis. 1999;143(2):285-297.

59. Stalenhoef AF, de Graaf J, Wittekoek ME, Bredie SJ, Demacker PN, Kastelein JJ. The effect of concentrated n-3 fatty acids versus gemfibrozil on plasma lipoproteins, low density lipoprotein heterogeneity and oxidizability in patients with hypertriglyceridemia. Atherosclerosis. 2000;153(1):129-138.

60. Balk E, Chung M, Lichtenstein A, et al. Effects of omega-3 fatty acids on cardiovascular risk factors and intermediate markers of cardiovascular disease. Evid Rep Technol Assess (Summ). 2004(93):1-6.

61. Rustan AC, Nossen JO, Christiansen EN, Drevon CA. Eicosapentaenoic acid reduces hepatic synthesis and secretion of triacylglycerol by decreasing the activity of acyl-coenzyme A:1,2-diacylglycerol acyltransferase. J Lipid Res. 1988;29(11):1417-1426. 
62. Jump DB. Fatty acid regulation of gene transcription. Crit Rev Clin Lab Sci. 2004;41(1):41-78.

63. Lee SS, Chan WY, Lo CK, Wan DC, Tsang DS, Cheung WT. Requirement of PPAR-alpha in maintaining phospholipid and triacylglycerol homeostasis during energy deprivation. J Lipid Res. 2004;45(11):2025-2037.

64. Sampath H, Ntambi JM. Polyunsaturated fatty acid regulation of gene expression. Nutr Rev. 2004;62(9):333-339.

65. Bays HE, Tighe AP, Sadovsky R, Davidson MH. Prescription omega-3 fatty acids and their lipid effects: Physiologic mechanisms of action and clinical implications. Expert Rev Cardiovasc Ther. 2008;6(3):391-409.

66. McKenney JM, Sica D. Role of prescription omega-3 fatty acids in the treatment of hypertriglyceridemia. Pharmacotherapy. 2007;27(5):715-728.

67. Chan DC, Watts GF, Barrett PH, Beilin LJ, Redgrave TG, Mori TA. Regulatory effects of HMG CoA reductase inhibitor and fish oils on apolipoprotein B-100 kinetics in insulin-resistant obese male subjects with dyslipidemia. Diabetes. 2002;51(8):2377-2386.

68. Robinson JG, Stone NJ. Antiatherosclerotic and antithrombotic effects of omega-3 fatty acids. Am J Cardiol. 2006;98(4A):39i-49i.

69. Maki K, Davidson M, Bays H, Stein E, Shalwitz R, Doyle R. Effects of omega-3-acid ethyl esters on LDL particle size in subjects with hypertriglyceridemia despite statin therapy. FASEB J. 2007;21:231-2.

70. Mozaffarian D, Geelen A, Brouwer IA, Geleijnse JM, Zock PL, Katan MB. Effect of fish oil on heart rate in humans: A meta-analysis of randomized controlled trials. Circulation. 2005;112(13):1945-1952.

71. Leaf A, Kang JX, Xiao YF. Fish oil fatty acids as cardiovascular drugs. Curr Vasc Pharmacol. 2008;6(1):1-12.

72. Verkerk AO, van Ginneken AC, Berecki G, et al. Incorporated sarcolemmal fish oil fatty acids shorten pig ventricular action potentials. Cardiovasc Res. 2006;70(3):509-520.

73. Sarrazin JF, Comeau G, Daleau P, et al. Reduced incidence of vagally induced atrial fibrillation and expression levels of connexins by $\mathrm{n}-3$ polyunsaturated fatty acids in dogs. J Am Coll Cardiol. 2007;50(15):1505-1512.

74. Li Y, Kang JX, Leaf A. Differential effects of various eicosanoids on the production or prevention of arrhythmias in cultured neonatal rat cardiac myocytes. Prostaglandins. 1997;54(2):511-530.

75. Takayama K, Yuhki K, Ono K, et al. Thromboxane A2 and prostaglandin F2alpha mediate inflammatory tachycardia. Nat Med. 2005;11(5):562-566.

76. Anand RG, Alkadri M, Lavie CJ, Milani RV. The role of fish oil in arrhythmia prevention. J Cardiopulm Rehabil Prev. 2008;28(2):92-98.

77. Christensen JH, Korup E, Aaroe J, et al. Fish consumption, n-3 fatty acids in cell membranes, and heart rate variability in survivors of myocardial infarction with left ventricular dysfunction. Am J Cardiol. 1997;79(12):1670-1673.

78. Cawood AL, Ding R, Napper FL, et al. Long chain omega-3 fatty acids enter advanced atherosclerotic plaques and are associated with decreased inflammation and decreased inflammatory gene expression. Rome, Italy; 2006 International Symposium on Atherosclerosis; 2006 June 18-22.

79. O'Keefe JH, Jr Abuissa H, Sastre A, Steinhaus DM, Harris WS. Effects of omega-3 fatty acids on resting heart rate, heart rate recovery after exercise, and heart rate variability in men with healed myocardial infarctions and depressed ejection fractions. Am J Cardiol. 2006;97(8):1127-1130.

80. Hamaad A, Kaeng Lee W, Lip GY, MacFadyen RJ. Oral omega n3-PUFA therapy (Omacor) has no impact on indices of heart rate variability in stable post myocardial infarction patients. Cardiovasc Drugs Ther. 2006;20(5):359-364.

81. Russo C, Olivieri O, Girelli D, et al. Omega-3 polyunsaturated fatty acid supplements and ambulatory blood pressure monitoring parameters in patients with mild essential hypertension. J Hypertens. 1995; 13(12 Pt 2):1823-1826.

82. Brouwer IA, Zock PL, Camm AJ, et al. Effect of fish oil on ventricular tachyarrhythmia and death in patients with implantable cardioverter defibrillators: The Study on Omega-3 Fatty Acids and Ventricular Arrhythmia (SOFA) randomized trial. JAMA. 2006;295(22): 2613-2619.

83. Leaf A, Albert CM, Josephson M, et al. Prevention of fatal arrhythmias in high-risk subjects by fish oil n-3 fatty acid intake. Circulation. 2005;112(18):2762-2768.
84. Raitt MH, Connor WE, Morris C, et al. Fish oil supplementation and risk of ventricular tachycardia and ventricular fibrillation in patients with implantable defibrillators: A randomized controlled trial. JAMA. 2005;293(23):2884-2891.

85. Vargiu R, Littarru GP, Faa G, Mancinelli R. Positive inotropic effect of coenzyme Q10, omega-3 fatty acids and propionyl-L-carnitine on papillary muscle force-frequency responses of BIO TO-2 cardiomyopathic Syrian hamsters. Biofactors. 2008;32(1-4):135-144.

86. Duda MK, O’Shea KM, Tintinu A, et al. Fish oil, but not flaxseed oil, decreases inflammation and prevents pressure overload-induced cardiac dysfunction. Cardiovasc Res. 2009;81(2):319-327.

87. Mozaffarian D, Gottdiener JS, Siscovick DS. Intake of tuna or other broiled or baked fish versus fried fish and cardiac structure, function, and hemodynamics. Am J Cardiol. 2006;97(2):216-222.

88. McLennan PL, Barnden LR, Bridle TM, Abeywardena MY, Charnock JS. Dietary fat modulation of left ventricular ejection fraction in the marmoset due to enhanced filling. Cardiovasc Res. 1992;26(9):871-877.

89. Peoples GE, McLennan PL, Howe PR, Groeller H. Fish oil reduces heart rate and oxygen consumption during exercise. $J$ Cardiovasc Pharmacol. 2008;52(6):540-547.

90. Pepe S, McLennan PL. Cardiac membrane fatty acid composition modulates myocardial oxygen consumption and postischemic recovery of contractile function. Circulation. 2002;105(19):2303-2308.

91. Pepe S, McLennan PL. (n-3) Long chain PUFA dose-dependently increase oxygen utilization efficiency and inhibit arrhythmias after saturated fat feeding in rats. $J$ Nutr. 2007;137(11):2377-2383.

92. Geleijnse JM, Giltay EJ, Grobbee DE, Donders AR, Kok FJ. Blood pressure response to fish oil supplementation: Meta-regression analysis of randomized trials. J Hypertens. 2002;20(8):1493-1499.

93. Bonaa KH, Bjerve KS, Straume B, Gram IT, Thelle D. Effect of eicosapentaenoic and docosahexaenoic acids on blood pressure in hypertension. A population-based intervention trial from the Tromso study. N Engl J Med. 1990;322(12):795-801.

94. Nordoy A, Hansen JB, Brox J, Svensson B. Effects of atorvastatin and omega-3 fatty acids on LDL subfractions and postprandial hyperlipemia in patients with combined hyperlipemia. Nutr Metab Cardiovasc Dis. 2001;11(1):7-16.

95. Andreassen AK, Hartmann A, Offstad J, Geiran O, Kvernebo K, Simonsen S. Hypertension prophylaxis with omega-3 fatty acids in heart transplant recipients. J Am Coll Cardiol. 1997;29(6):1324-1331.

96. Matsumoto T, Nakayama N, Ishida K, Kobayashi T, Kamata K. Eicosapentaenoic acid improves imbalance between vasodilator and vasoconstrictor actions of endothelium-derived factors in mesenteric arteries from rats at chronic stage of type 2 diabetes. J Pharmacol Exp Ther. 2009;329(1):324-334.

97. Omura M, Kobayashi S, Mizukami Y, et al. Eicosapentaenoic acid (EPA) induces $\mathrm{Ca}(2+)$-independent activation and translocation of endothelial nitric oxide synthase and endothelium-dependent vasorelaxation. FEBS Lett. 2001;487(3):361-366.

98. Mori TA, Watts GF, Burke V, Hilme E, Puddey IB, Beilin LJ. Differential effects of eicosapentaenoic acid and docosahexaenoic acid on vascular reactivity of the forearm microcirculation in hyperlipidemic, overweight men. Circulation. 2000;102(11):1264-1269.

99. McVeigh GE, Brennan GM, Cohn JN, Finkelstein SM, Hayes RJ, Johnston GD. Fish oil improves arterial compliance in non-insulindependent diabetes mellitus. Arterioscler Thromb. 1994;14(9): $1425-1429$.

100. Hansen JB, Lyngmo V, Svensson B, Nordoy A. Inhibition of exerciseinduced shortening of bleeding time by fish oil in familial hypercholesterolemia (type IIa). Arterioscler Thromb. 1993;13(1):98-104.

101. Goodfellow J, Bellamy MF, Ramsey MW, Jones CJ, Lewis MJ. Dietary supplementation with marine omega-3 fatty acids improve systemic large artery endothelial function in subjects with hypercholesterolemia. J Am Coll Cardiol. 2000;35(2):265-270.

102. Engler MM, Engler MB, Malloy M, et al. Docosahexaenoic acid restores endothelial function in children with hyperlipidemia: Results from the EARLY study. Int J Clin Pharmacol Ther. 2004;42(12):672-679. 
103. Agren JJ, Vaisanen S, Hanninen O, Muller AD, Hornstra G. Hemostatic factors and platelet aggregation after a fish-enriched diet or fish oil or docosahexaenoic acid supplementation. Prostaglandins Leukot Essent Fatty Acids. 1997;57(4-5):419-421.

104. Kim DN, Eastman A, Baker JE, et al. Fish oil, atherogenesis, and thrombogenesis. Ann N Y Acad Sci. 1995;748:474 480; discussion 480-481.

105. Mori TA, Beilin LJ, Burke V, Morris J, Ritchie J. Interactions between dietary fat, fish, and fish oils and their effects on platelet function in men at risk of cardiovascular disease. Arterioscler Thromb Vasc Biol. 1997;17(2):279-286.

106. Westerveld HT, de Graaf JC, van Breugel HH, et al. Effects of lowdose EPA-E on glycemic control, lipid profile, lipoprotein(a), platelet aggregation, viscosity, and platelet and vessel wall interaction in NIDDM. Diabetes Care. 1993;16(5):683-688.

107. Woodman RJ, Mori TA, Burke V, et al. Effects of purified eicosapentaenoic acid and docosahexaenoic acid on platelet, fibrinolytic and vascular function in hypertensive type 2 diabetic patients. Atherosclerosis. 2003;166(1):85-93.

108. Tsuruta K, Ogawa H, Yasue H, et al. Effect of purified eicosapentaenoate ethyl ester on fibrinolytic capacity in patients with stable coronary artery disease and lower extremity ischaemia. Coron Artery Dis. 1996;7(11):837-842.

109. Nordoy A, Bonaa KH, Sandset PM, Hansen JB, Nilsen H. Effect of omega-3 fatty acids and simvastatin on hemostatic risk factors and postprandial hyperlipemia in patients with combined hyperlipemia Arterioscler Thromb Vasc Biol. 2000;20(1):259-265.

110. Lee KW, Blann AD, Lip GY. Effects of omega-3 polyunsaturated fatty acids on plasma indices of thrombogenesis and inflammation in patients post-myocardial infarction. Thromb Res. 2006;118(3):305-312

111. Knapp HR. Dietary fatty acids in human thrombosis and hemostasis. Am J Clin Nutr. 1997;65(5 Suppl):1687S-1698S.

112. Hansen JB, Olsen JO, Wilsgard L, Lyngmo V, Svensson B. Comparative effects of prolonged intake of highly purified fish oils as ethyl ester or triglyceride on lipids, haemostasis and platelet function in normolipaemic men. Eur J Clin Nutr. 1993;47(7):497-507.

113. Nilsen DW, Dalaker K, Nordoy A, et al. Influence of a concentrated ethylester compound of n-3 fatty acids on lipids, platelets and coagulation in patients undergoing coronary bypass surgery. Thromb Haemost. 1991;66(2):195-201.

114. Smith P, Arnesen H, Opstad T, Dahl KH, Eritsland J. Influence of highly concentrated n-3 fatty acids on serum lipids and hemostatic variables in survivors of myocardial infarction receiving either oral anticoagulants or matching placebo. Thromb Res. 1989;53(5):467-474.

115. Eritsland J, Arnesen H, Smith P, Seljeflot I, Dahl K. Effects of highly concentrated omega-3 polyunsaturated fatty acids and acetylsalicylic acid, alone and combined, on bleeding time and serum lipid profile. $J$ Oslo City Hosp. 1989;39(8-9):97-101.

116. Eritsland J, Arnesen H, Gronseth K, Fjeld NB, Abdelnoor M. Effect of dietary supplementation with n-3 fatty acids on coronary artery bypass graft patency. Am J Cardiol. 1996;77(1):31-36.

117. Harris WS. Expert opinion: Omega-3 fatty acids and bleeding - cause for concern? Am J Cardiol. 2007;99(6A):44C-46C.

118. Moreno JJ, Mitjavila MT. The degree of unsaturation of dietary fatty acids and the development of atherosclerosis (review). J Nutr Biochem. 2003;14(4):182-195.

119. Johansen O, Brekke M, Seljeflot I, Abdelnoor M, Arnesen H. n-3 fatty acids do not prevent restenosis after coronary angioplasty: Results from the CART study. Coronary Angioplasty Restenosis Trial. $J$ Am Coll Cardiol. 1999;33(6):1619-1626.

120. Gapinski JP, VanRuiswyk JV, Heudebert GR, Schectman GS. Preventing restenosis with fish oils following coronary angioplasty. A meta-analysis. Arch Intern Med. 1993;153(13):1595-1601.

121. O'Connor GT, Malenka DJ, Olmstead EM, Johnson PS, Hennekens CH. A meta-analysis of randomized trials of fish oil in prevention of restenosis following coronary angioplasty. Am J Prev Med. 1992;8(3):186-192.

122. Thies F, Garry JM, Yaqoob P, et al. Association of n-3 polyunsaturated fatty acids with stability of atherosclerotic plaques: A randomised controlled trial. Lancet. 2003;361(9356):477-485.
123. Kaminski WE, Jendraschak E, Kiefl R, von Schacky C. Dietary omega-3 fatty acids lower levels of platelet-derived growth factor mRNA in human mononuclear cells. Blood. 1993;81(7): 1871-1879.

124. Mehra MR, Lavie CJ, Ventura HO, Milani RV. Fish oils produce antiinflammatory effects and improve body weight in severe heart failure. J Heart Lung Transplant. 2006;25(7):834-838.

125. Moreno JJ. Differential effects of arachidonic and eicosapentaenoic acid-derived eicosanoids on polymorphonuclear transmigration across endothelial cell cultures. J Pharmacol Exp Ther. 2009;331(3): 1111-1117.

126. Mori TA, Woodman RJ, Burke V, Puddey IB, Croft KD, Beilin LJ. Effect of eicosapentaenoic acid and docosahexaenoic acid on oxidative stress and inflammatory markers in treated-hypertensive type 2 diabetic subjects. Free Radic Biol Med. 2003;35(7):772-781.

127. Moreno JJ, Carbonell T, Sanchez T, Miret S, Mitjavila MT. Olive oil decreases both oxidative stress and the production of arachidonic acid metabolites by the prostaglandin $\mathrm{G} / \mathrm{H}$ synthase pathway in rat macrophages. J Nutr. 2001;131(8):2145-2149.

128. Marchioli R. Treatment with n-3 polyunsaturated fatty acids after myocardial infarction: Results of GISSI-Prevenzione Trial. Eur Heart J. 2001;3(Suppl D):D85-D97.

129. Rauch B, Schiele R, Schneider S, et al. Highly purified omega-3 fatty acids for secondary prevention of sudden cardiac death after myocardial infarction-aims and methods of the OMEGA-study. Cardiovasc Drugs Ther. 2006;20(5):365-375.

130. Senges J, Schiele R, Schneider S, et al. Randomized trial of omega-3 fatty acids on top of modern therapy after acute myocardial infarction: The OMEGA trial. Paper presented at: 58th Annual Scientific Session of the American College of Cardiology, 2009. 2009 Mar 29-31, Orlando (FL).

131. Yamagishi $\mathrm{K}$, Iso $\mathrm{H}$, Date $\mathrm{C}$, et al. Fish, omega-3 polyunsaturated fatty acids, and mortality from cardiovascular diseases in a nationwide community-based cohort of Japanese men and women: The JACC (Japan Collaborative Cohort Study for Evaluation of Cancer Risk) study. $J$ Am Coll Cardiol. 2008;52(12):988-996.

132. Davidson MH, Stein EA, Bays HE, et al. Efficacy and tolerability of adding prescription omega-3 fatty acids $4 \mathrm{~g} / \mathrm{d}$ to simvastatin $40 \mathrm{mg} / \mathrm{d}$ in hypertriglyceridemic patients: An 8-week, randomized, double-blind, placebo-controlled study. Clin Ther. 2007;29(7):1354-1367.

133. Verboom $\mathrm{CN}$. Highly purified omega-3 polyunsaturated fatty acids are effective as adjunct therapy for secondary prevention of myocardial infarction. Herz. 2006;31 Suppl 3:49-59.

134. Smith SC Jr, Allen J, Blair SN, et al. AHA/ACC guidelines for secondary prevention for patients with coronary and other atherosclerotic vascular disease: 2006 update endorsed by the National Heart, Lung, and Blood Institute. J Am Coll Cardiol. 2006;47(10):2130-2139.

135. Third Report of the National Cholesterol Education Program (NCEP) Expert Panel on Detection, Evaluation, and Treatment of High Blood Cholesterol in Adults (Adult Treatment Panel III) final report. Circulation. 2002;106(25):3143-3421.

136. De Backer G, Ambrosioni E, Borch-Johnsen K, et al. European guidelines on cardiovascular disease prevention in clinical practice. Third Joint Task Force of European and Other Societies on Cardiovascular Disease Prevention in Clinical Practice. Eur Heart J. 2003;24(17):1601-1610.

137. Priori SG, Aliot E, Blomstrom-Lundqvist C, et al. Update of the guidelines on sudden cardiac death of the European Society of Cardiology. Eur Heart J. 2003;24(1):13-15.

138. Van de Werf F, Ardissino D, Betriu A, et al. Management of acute myocardial infarction in patients presenting with ST-segment elevation. The Task Force on the Management of Acute Myocardial Infarction of the European Society of Cardiology. Eur Heart J. 2003;24(1): $28-66$.

139. Sacks FM, Stone PH, Gibson CM, Silverman DI, Rosner B, Pasternak RC. Controlled trial of fish oil for regression of human coronary atherosclerosis. HARP Research Group. J Am Coll Cardiol. 1995;25(7):1492-1498. 
140. Singh RB, Niaz MA, Sharma JP, Kumar R, Rastogi V, Moshiri M. Randomized, double-blind, placebo-controlled trial of fish oil and mustard oil in patients with suspected acute myocardial infarction: the Indian experiment of infarct surviva-4. Cardiovasc Drugs Ther. 1997;11(3):485-491.

141. Leng GC, Lee AJ, Fowkes FG, et al. Randomized controlled trial of gamma-linolenic acid and eicosapentaenoic acid in peripheral arterial disease. Clin Nutr. 1998;17(6):265-271.

142. von Schacky C, Angerer P, Kothny W, Theisen K, Mudra H. The effect of dietary omega-3 fatty acids on coronary atherosclerosis. A randomized, double-blind, placebo-controlled trial. Ann Intern Med. 1999;130(7):554-562.
143. Nilsen DW, Albrektsen G, Landmark K, Moen S, Aarsland T, Woie L. Effects of a high-dose concentrate of n-3 fatty acids or corn oil introduced early after an acute myocardial infarction on serum triacylglycerol and HDL cholesterol. Am J Clin Nutr. 2001;74(1):50-56.

144. Yokoyama M, Origasa H, Matsuzaki M, et al. Effects of eicosapentaenoic acid on major coronary events in hypercholesterolaemic patients (JELIS): a randomised open-label, blinded endpoint analysis. Lancet. 2007;369(9567):1090-1098.

\section{Publish your work in this journal}

The Journal of Multidisciplinary Healthcare is an international, peerreviewed open-access journal that aims to represent and publish research in healthcare areas delivered by practitioners of different disciplines. This includes studies and reviews conducted by multidisciplinary teams as well as research which evaluates the results or conduct of such teams or healthcare processes in general. The journal covers a wide range of areas and welcomes submission from practitioners at all levels, from all over the world. The manuscript management system is completely online and includes a very quick and fair peer-review system. Visit http://www.dovepress.com/testimonials.php to read real quotes from published authors. 